\title{
CLAVES Y DATOS NUEVOS DE LAS ESPECIES IBÉRICAS DEL GÉNERO CHELOSTOMA LATREILLE, 1809 (HYMENOPTERA, MEGACHILIDAE, OSMIINI) ${ }^{1}$
}

\author{
F. Torres*, C. Ornosa** \& F. J. Ortiz-Sánchez***
}

\section{RESUMEN}

F. Torres, C. Ornosa \& F. J. Ortiz-Sánchez. 2012. Claves y datos nuevos de las especies ibéricas del género Chelostoma Latreille, 1809 (Hymenoptera, Megachilidae, Osmiini). Graellsia, 68(2): 263-280.

El trabajo actual, dentro de la revisión que se está realizando de la familia Megachilidae en la fauna ibérica, incluye las claves de identificación para las especies del género Chelostoma Latreille, 1809. Las claves se acompañan de ilustraciones para su reconocimiento. El estudio incluye también registros nuevos y otros datos de interés, ya que varias de ellas se conocían escasamente en el territorio ibérico.

Palabras clave: Hymenoptera; Megachilidae; Osmiini; Chelostoma; claves; Península Ibérica; nuevos registros.

\section{ABSTRACT}

F. Torres, C. Ornosa \& F. J. Ortiz-Sánchez. 2012. Keys and new data about lberian Chelostoma Latreille, 1809 (Hymenoptera, Megachilidae, Osmiini). Graellsia, 68(2): 263280 (in Spanish).

This paper includes keys to the Iberian species of genus Chelostoma (Hymenoptera, Megachilidae, Osmiini) as part of the ongoing general revision of the Iberian taxa of Megachilidae. The accompanying illustrations should make identification easier. Information about new records and other interesting data are included too, since several of these species had only rarely been recorded from the lberian area.

Key words: Hymenoptera; Megachilidae; Osmiini; Chelostoma; keys; Iberian Peninsula; new records.

* Departamento de Biología Animal, Ecología, Parasitología y Edafología. Universidad de Salamanca. Campus Miguel de Unamuno s/n. E-37071 Salamanca, España.E-mail: torres@usal.es

** Departamento de Zoología y Antropología Física. Facultad de Biología. Universidad Complutense. c/ José Antonio Nováis, 2. E-28040 Madrid, España. E-mail: paddy@bio.ucm.es

*** Grupo de Investigación "Transferencia de I+D en el Área de Recursos Naturales". Universidad de Almería. E-04120 La Cañada de San Urbano (Almería), España. E-mail: fjortiz@ual.es

Subvencionado por el Proyecto CGL2007-60877 


\section{Introducción}

En el género Chelostoma se incluyen especies que se distribuyen por el reino Holártico y la región Oriental. En la fauna ibérica aparecen ocho, varias de las cuales contaban hasta ahora con muy escasas citas en España (Ornosa et al., 2006; Ortiz-Sánchez, 2012). Los datos bibliográficos sobre este género en la Península Ibérica se encuentran sumamente dispersos en obras generalistas, básicamente de carácter faunístico, siendo inexistentes los trabajos monográficos dedicados al mismo en esta área de estudio.

El estudio actual presenta las claves de identificación para los subgéneros ibéricos (Chelostoma, Gyrodromella Michener, 1997 y Foveosmia Warncke, 1991) y sus especies, estas últimas separadas por sexos. Las claves son originales, así como los dibujos y fotografías, aunque se han manejado las realizadas previamente por los autores que han tratado el tema para especies europeas del género (Amiet et al., 2004; Banaszak \& Romasenko, 1998; Benoist, 1929; Scheuchl, 1996).

Chelostoma es un género muy uniforme, de especies morfológicamente similares, reunidas desde hace tiempo en subgéneros de los que existen tres en el territorio mediterráneo occidental (Michener, 2007) que, asimismo, se hallan representados en la Península Ibérica (Ornosa et al., 2006). No obstante, algunos autores incluyen a Chelostoma, junto con Heriades Spinola, 1808, dentro del género Osmia Panzer, 1806 (Warncke, 1986; Westrich \& Dathe, 1997; Dubitzky et al., 2005).

En su biología, se trata de especies de finales de primavera y verano. La mayoría son oligolécticas, estrechamente asociadas a Campanuláceas y Ranunculáceas. Nidifican en cavidades preexistentes en madera, construyendo nidos lineales con celdas sencillas, separadas por particiones transversas formadas por pequeñas partículas de tierra y arena amasada con néctar (Banaszak \& Romasenko, 1998; Müller, 2012).

Trabajos recientes, en los que la utilización de técnicas moleculares aporta nuevos datos, muestran una clara evidencia de que Chelostoma es un grupo monofilético hermano del resto de especies de la tribu Osmiini y permiten fundamentar los diferentes subgéneros y la asignación de especies a los mismos (Praz et al., 2008; Müller, 2012). En este artículo, siguiendo el criterio de estas publicaciones más recientes, se mantiene la validez de los distintos subgéneros (Ornosa et al. 2006; Michener, 2007; Praz et al., 2008; Müller, 2012).

\section{Material y métodos}

Para realizar este estudio se han revisado las colecciones de las siguientes instituciones: Museo Nacional de Ciencias Naturales de Madrid (MNCN), Instituto Valenciano de Investigaciones Agrarias de Valencia (IVIA), Estación Experimental de Zonas Áridas de Almería (EEZA), Departamento de Biología Animal, Ecología, Parasitología y Edafología de la Universidad de Salamanca (USAL) y Departamento de Zoología y Antropología Física de la Universidad Complutense de Madrid (UCM), además de especímenes del Museo Nacional de Historia Natural de París, del Museo Zoológico de Berlín y la colección particular de uno de los autores (F. J. Ortiz-Sánchez) (FJOS). Del material examinado, solo se refieren en el texto los ejemplares que representan nuevos registros o citas corregidas o enmendadas.

\section{CARACTERES DIAGNÓSTICOS Y TERMINOLOGÍA EMPLEADA}

Las especies de este género (fig. 1) presentan un aspecto externo de tipo heriadiforme (Michener, 2007), con el cuerpo delgado, cilíndrico, de color negro y cubierto de corta pubescencia pálida, con la escultura más atenuada y menos grosera que en Heriades. La mayoría alcanza longitudes entre 3,4 y 9,0 $\mathrm{mm}$, aunque en algunas especies, no presentes en la Península Ibérica, se pueden alcanzar tamaños mayores.

Las hembras se caracterizan por su labro sin orla pilosa y fuertemente alargado, cuya base es visible sobre las mandíbulas cerradas. Estas, en las hembras, están provistas normalmente de largas setas en sus márgenes internos y son usualmente anchas en la base, estrechándose bastante en el ápice, el cual es bi o tridentado. En las antenas, se diferencian los componentes habituales, el escapo basal, el pedicelo y un flagelo con 10 (en las hembras) u 11 (en los machos) flagelómeros o artejos antenales. Como norma general, el primer artejo flagelar se toma como el tercero de la antena $\left(\mathrm{A}_{3}\right)$ y los flagelómeros se representan abreviadamente por medio de una A, seguida del subíndice del ordinal correspondiente. El clípeo puede estar ornamentado con un tubérculo o ser uniformemente convexo, con un saliente o sin él y con el borde anterior liso o denticulado. Presentan palpos maxilares de tres artejos.

El tórax es oval-elongado. Las líneas parapsidales son normalmente más largas que la mitad de la 


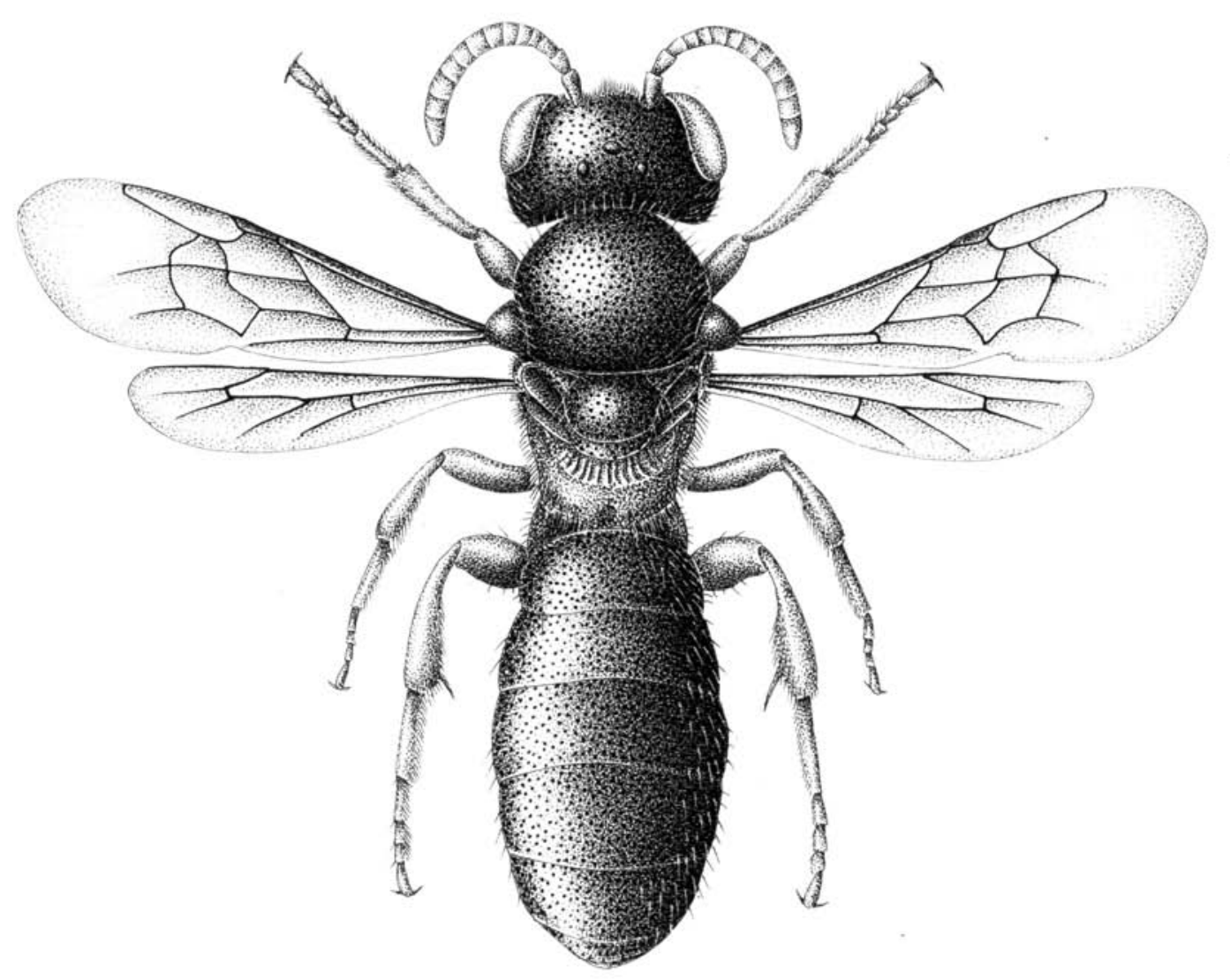

Fig. 1.- Chelostoma campanularum $0^{7}$. Hábitus.

Fig. 1.- Chelostoma campanularum $0^{\top}$. Habitus.

longitud tegular. Escutelo, postescutelo y área horizontal del propodeo se hallan en un solo plano. El área horizontal del propodeo está bien desarrollada (patente), es ancha y, a veces, está separada del área vertical por una carena. El escutelo no está dentado en las axilas. En el par de alas anterior, la celda marginal es grande, adelgazada en el extremo, y las dos celdas submarginales son casi iguales. Además, el $2^{\circ}$ nervio transverso-discoidal (o recurrente $2^{\circ}$ ) está situado más hacia el ápice del ala que el $2^{\circ}$ transverso-submarginal. En las patas, existen arolios entre las uñas.

En el gáster, como es usual, se designa a terguitos y esternitos, abreviadamente, por su inicial, es decir T y E, respectivamente, seguida de un subíndice que corresponde al ordinal del segmento gastral referido, con lo que, por ejemplo, el tercer terguito se abrevia como $\mathrm{T}_{3}$ y el quinto esternito como $\mathrm{E}_{5}$. El gáster es alargado, con escopa ventral en las hembras, y la forma, la pubescencia y las distintas estructuras de los esternitos gastrales son de valor taxonómico. $\mathrm{T}_{1}$ presenta una concavidad anterior y es convexo en su parte dorsal. El ápice de $\mathrm{T}_{7}$ en los machos tiene lóbulos o espinas (figs. 3b, 12a, 14b). Los terguitos gastrales pueden poseer bandas pilosas apicales o carecer de ellas. $\mathrm{T}_{6}$ de las hembras es triangularmente redondeado y se halla cubierto por una densa pubescencia blanquecina. La escopa gastral de las hembras es igualmente blanquecina. Los esternitos gastrales de los machos pueden estar más o menos abultados. $\mathrm{E}_{2}$ posee formaciones con distintos aspectos.

El tegumento, de color negro, presenta un punteado fuerte, incluso grosero, granulado en algunas zonas en ciertas especies. El color de la pubescencia o pilosidad varía desde el blanco al amarillo dorado. Se halla constituida por setas de una longitud variable según la zona del cuerpo. Normalmente tienen 

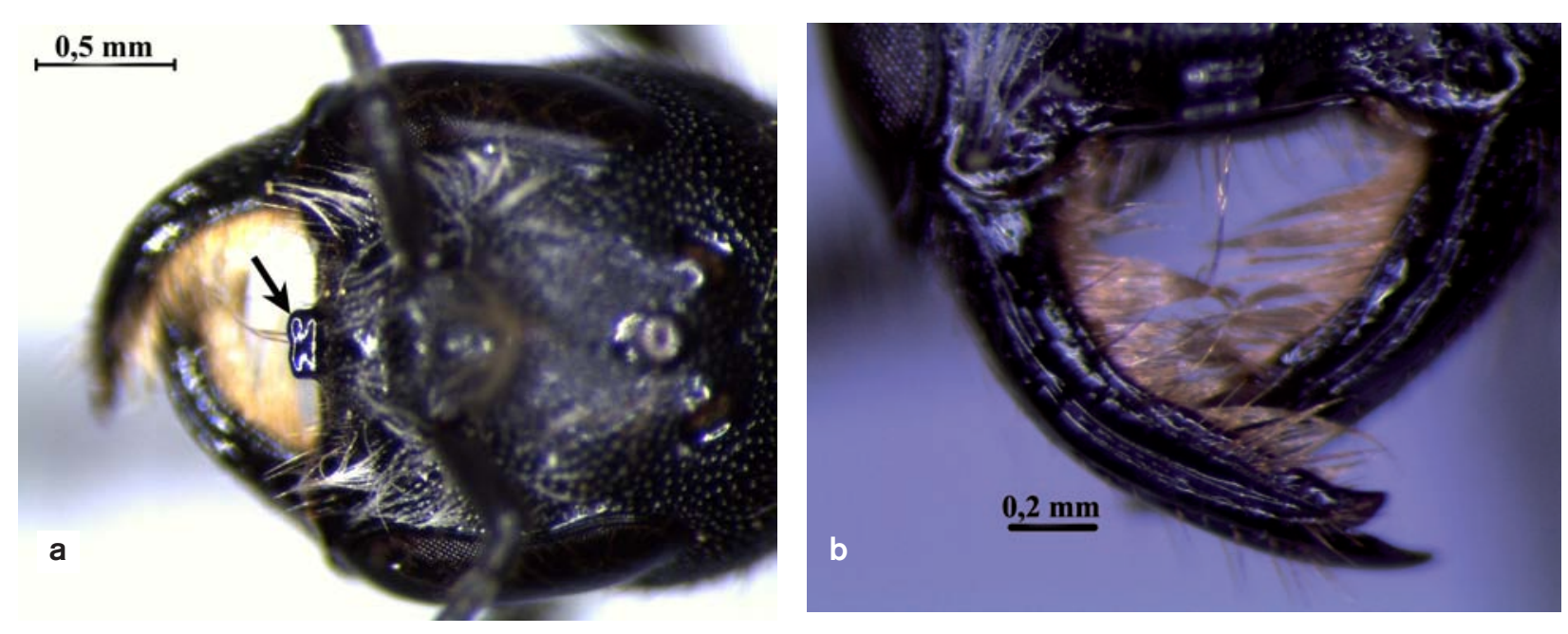

Fig. 2.- Chelostoma florisomne 오 . a) Clípeo y b) mandíbula.

Fig. 2.- Chelostoma florisomne 오 a) Clypeus and b) Mandible.

forma de pelo, delgado y largo o pueden ser más gruesas y cortas, incluso a modo de cerdas.

\section{Resultados y discusión}

\section{ESPECIES IBÉRICAS DE CHELOSTOMA LATREILLE, 1809}

Subgénero Chelostoma Latreille, 1809

Chelostoma (Chelostoma) edentulum Pérez, 1895

Chelostoma (Chelostoma) emarginatum (Nylander, 1856)

Chelostoma (Chelostoma) florisomne (Linnaeus, 1758)

Subgénero Foveosmia Warncke, 1991

Chelostoma (Foveosmia) campanularum (Kirby, 1802)

Chelostoma (Foveosmia) distinctum (Stöckhert, 1929)

Chelostoma (Foveosmia) foveolatum (Morawitz, 1868)

Subgénero Gyrodromella Michener, 1997

Chelostoma (Gyrodromella) nasutum Pérez, 1895

Chelostoma (Gyrodromella) rapunculi (Lepeletier, 1841)

\section{GÉNERO CHELOSTOMA}

\section{Clave de subgéneros $\left(\sigma^{x} \sigma^{x}\right.$ y $\circ$ \% $)$}

1. Líneas parapsidales más cortas que la longitud de la tégula. Machos con $\mathrm{T}_{\text {, }}$ provisto de dos lóbulos anchos y aplanados. Longitud del labro en las hembras claramente mayor del doble de su anchura; mandibula alargada, tan larga como el ancho de la cabeza

Chelostoma

- Líneas parapsidales de igual o mayor longitud que la de la tégula. Machos con $\mathrm{T}_{7}$ de otra forma. Longitud del labro en las hembras claramente menor de dos veces su anchura; mandíbula corta, poco más larga que la mitad de la anchura de la cabeza

2

2. Sin quilla preoccipital. Machos con protuberancia baja en $E_{2}$ en forma de giba redondeada. Hembras sin bandas apicales de setas en los terguitos ........ Foveosmia

- Quilla preoccipital pronunciada. Machos con protuberancia elevada en $\mathrm{E}_{2}$ de forma triangular o semicircular. Hembras con bandas apicales de setas en los terguitos

Gyrodromella

\section{Subgénero Chelostoma ( $ᄋ$ 우)}

1. Clípeo corto rematado anteriormente por una lámina levantada (fig. 2a); zona central mate. Mandíbulas finas y alargadas, muy curvadas, bidentadas (fig. 2b). Área horizontal del propodeo con fuertes arrugas. $T_{6}$ con escultura mucho más espesa y fina que la de los terguitos anteriores, cubierto de pilosidad de color pardusco. Escopa de color blanco amarillento. Longitud: 7-11 mm .

Ch. (Chelostoma) florisomne

- Clípeo plano o convexo, no rematado anteriormente por una lámina levantada. Mandíbulas rectas, tridentadas, al existir un pequeño diente en el centro del margen interno (figs. 4a, 6a). Área horizontal del propodeo plana, más larga, o al menos tan larga como el postescutelo, provista de finas arrugas longitudinales; área central pulida, lisa y brillante

2. Ápice del labro, en vista lateral, uniformemente engrosado desde la base al ápice (fig. 6b). Clípeo corto, casi plano y con densa puntuación en su base; en el centro es poco convexo y se halla deprimido transversalmente en el tercio distal; borde anterior ligeramente escotado, no denticulado. Antenas fuertemente claviformes (fig. $6 c) ; A_{6}$ tan largo como $A_{5}$ y más largo que $A_{7}$. Cabeza 
a

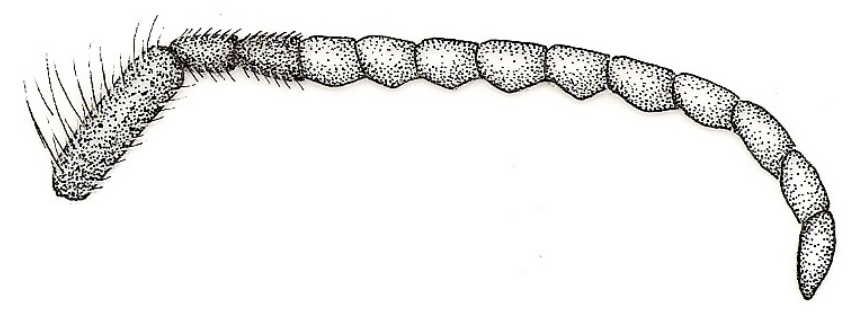

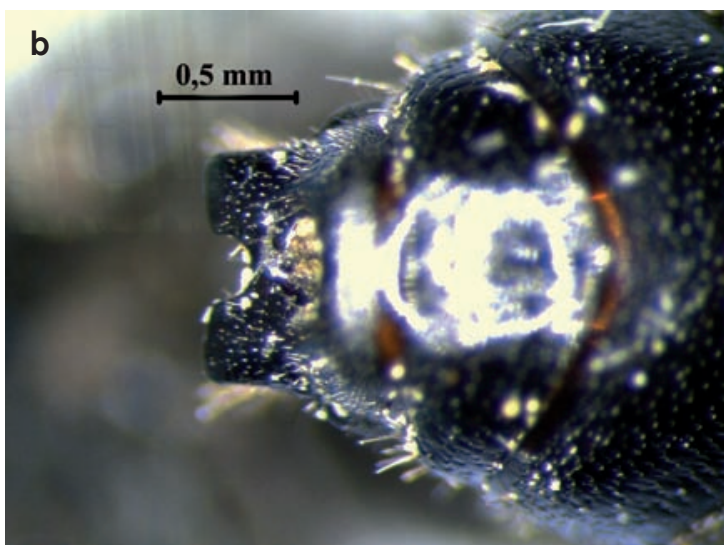
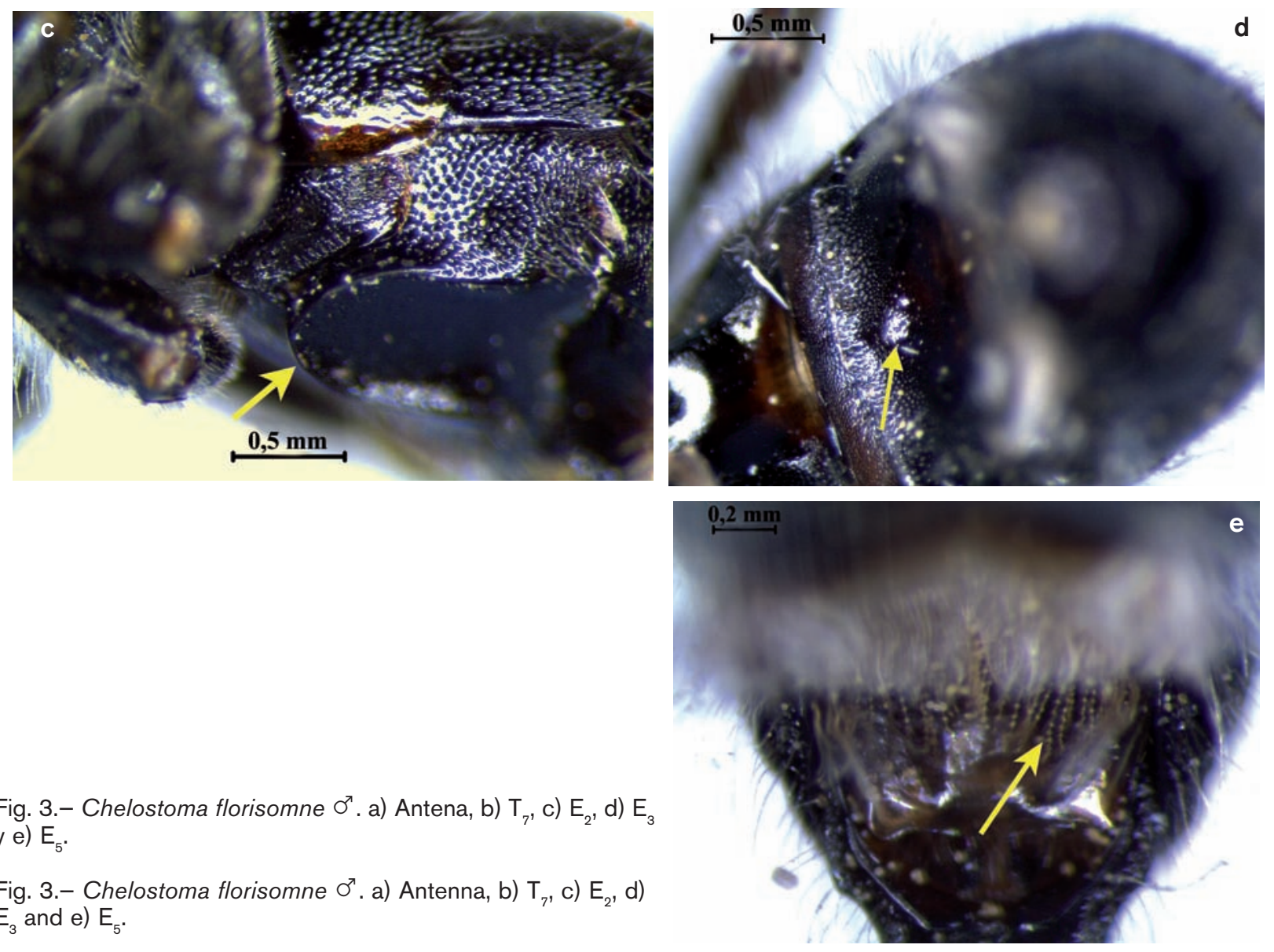

Subgénero Chelostoma $\left(\sigma^{x} \sigma^{x}\right)$

1. Flagelómeros antenales de $A_{8}$ a $A_{13}$ de color amarillo pardusco, salientes en la cara ventral, de modo que las antenas son aserradas (fig. 3a). Terguitos con más o menos setas. $T_{7}$ ahuecado en su parte media y escotado, dando lugar a dos lóbulos rectangulares (fig. 3b). $E_{2}$ con protuberancia en forma de herradura (fig. 3c), cóncava en su parte anterior, ocupando $2 / 3$ de la anchura 

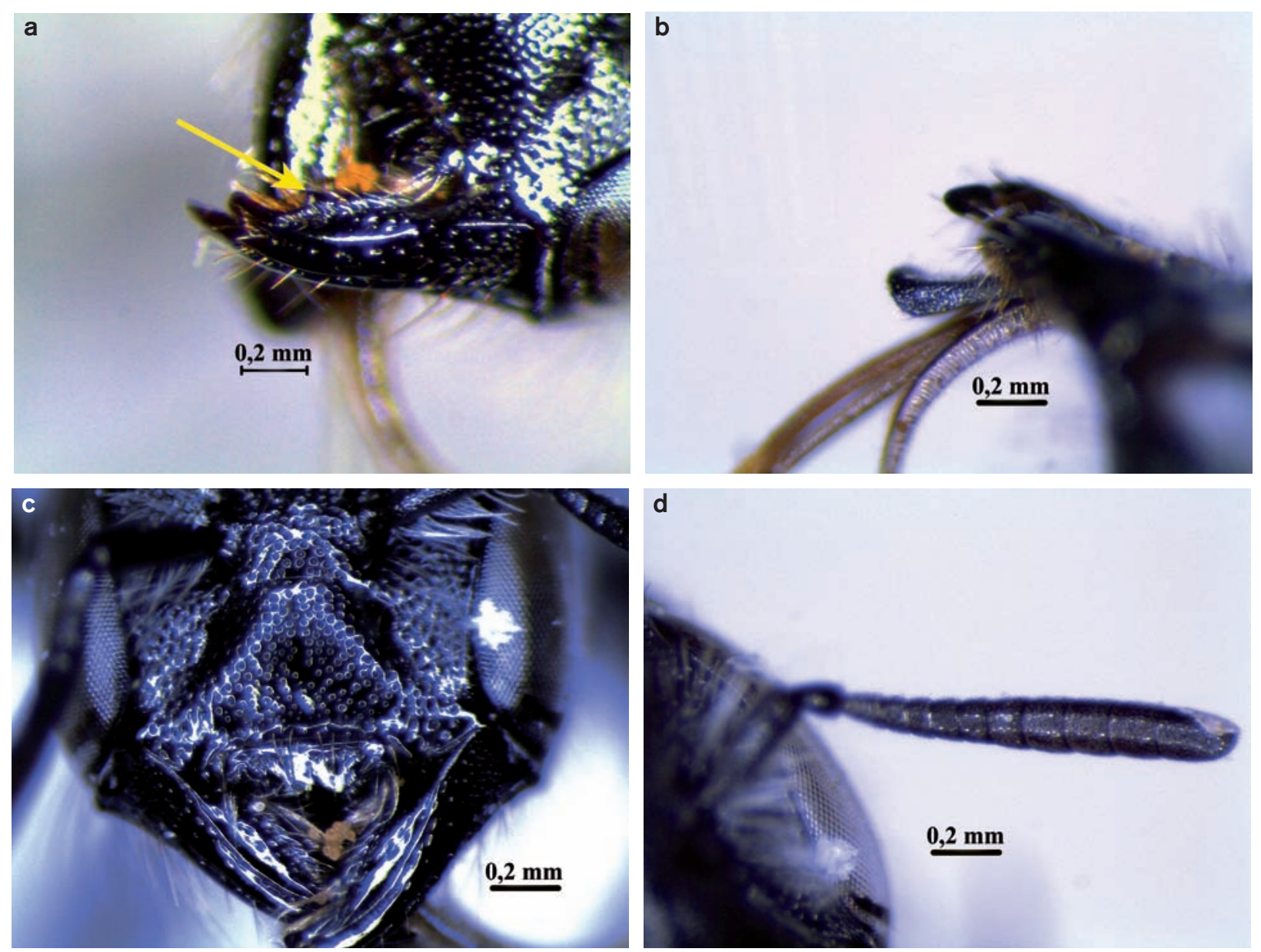

Fig. 4.- Chelostoma edentulum 오. a) Mandíbula. b) Labro (vista lateral). c) Clípeo. d) Antena.

Fig. 4.- Chelostoma edentulum 오 . a) Mandible. b) Labrum (lateral view). c) Clypeus. d) Antenna.

de $E_{2}$. $E_{3}$ con una emarginación semicircular en el centro del margen apical, formando una depresión ahueca$\mathrm{da}$, de color claro, brillante y sin setas (fig. 3d). $\mathrm{E}_{4}$ completamente cubierto de setas espesas y largas de color blanco amarillento. $\mathrm{E}_{5}$ cubierto de flecos de setas curvadas en espiral, trenzados o anudados (fig. $3 e$ ). $E_{6}$ más o menos visible. Longitud: $8-11 \mathrm{~mm}$

Ch. (Chelostoma) florisomne

- Flagelo antenal no aserrado. $E_{2}$ con una protuberancia en forma de herradura ocupando $2 / 3$ de la anchura de $E_{2}$. $E_{3}$ con setas espesas de color gris blanquecino en la parte basal y con una emarginación triangular en el centro del margen apical con dos grupos de cerdas negras en su borde basal (fig. $7 b$ ). $\mathrm{E}_{4}$ con setas espesas de color blanco a marrón amarillento y con un penacho de color amarillo pardusco en cada lado. $E_{5}$, normalmente oculto bajo $E_{4}$, con largos flecos de setas lisas en el borde distal (fig. 7c). $E_{6}$ oculto por $E_{5} \quad \ldots . .2$

2. Limpiador antenal del primer par de patas con el espolón ensanchado apicalmente y redondeado en el extremo (fig. $7 \mathrm{a}$ ). $\mathrm{T}_{7}$ provisto de una marcada hendidura semicircular en el borde, cuyo diámetro sobrepasa ampliamente un tercio de la anchura total del borde distal del terguito (fig. 7d); los dos lóbulos que la delimitan son ligeramente divergentes y de forma rectangular. Gonostilos con largas cerdas de color claro en su extremo; valvas peneanas fuertemente adelgazadas desde su centro al extremo apical, terminadas en punta más o menos aguda; en vista ventral, bordes internos regularmente convergentes hacia el extremo apical (figs. 7e, 7f). Longitud: 7-8 mm

Ch. (Chelostoma) emarginatum

- Limpiador antenal del primer par de patas con el espolón decreciente hacia el extremo, donde no es redondeado sino cuadrangular (fig. $5 \mathrm{a}$ ). $\mathrm{T}_{7}$ provisto de una marcada hendidura semicircular en el borde, cuyo diámetro no excede de un tercio de la anchura total del borde distal del terguito (fig. 5b); los dos lóbulos que la delimitan son paralelos y de forma rectangular. Gonostilos con largas cerdas de color oscuro, casi 

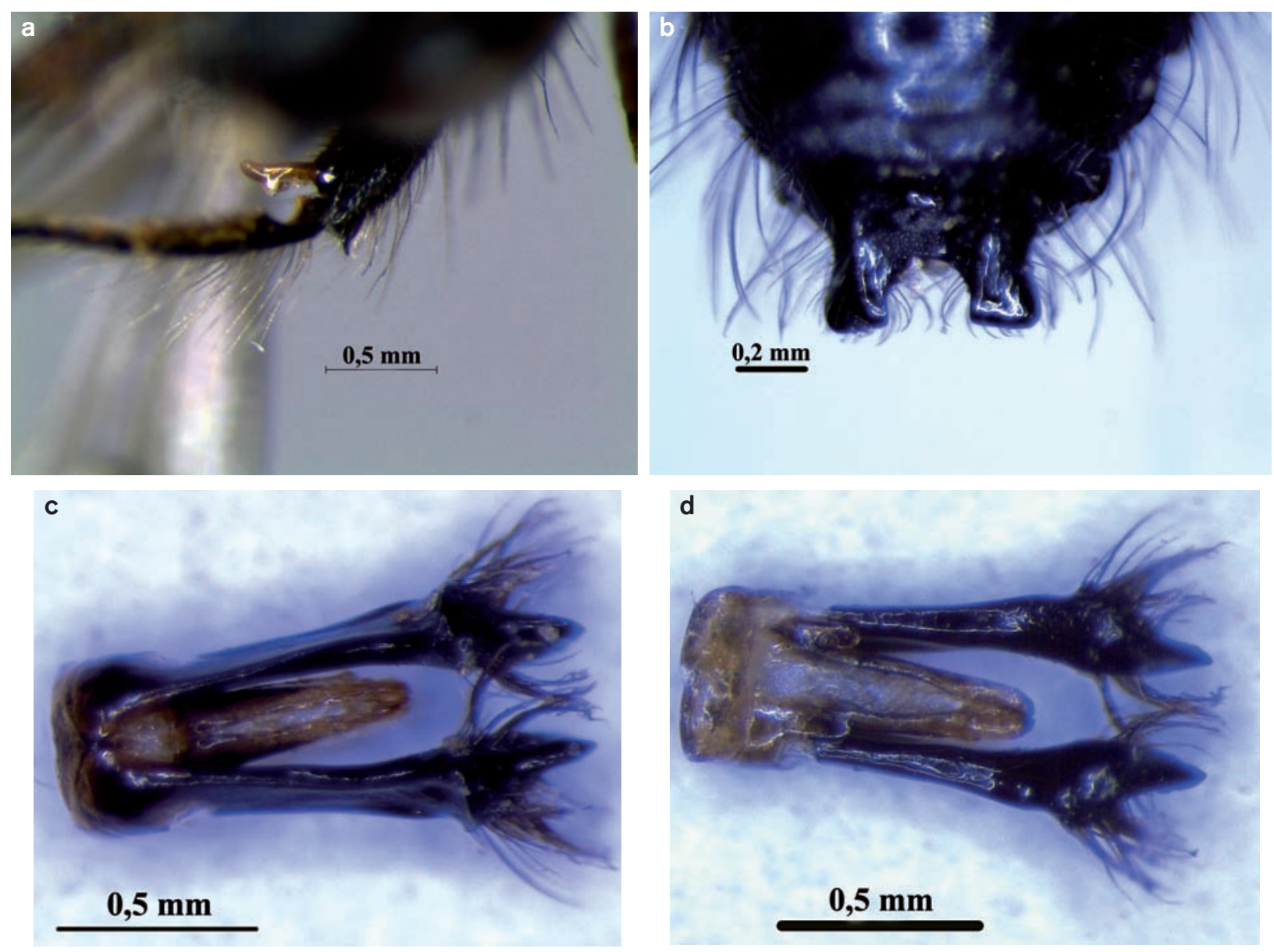

Fig 5.- Chelostoma edentulum $\sigma^{7}$. a) Espolón limpiador antenal. b) T. c) Genitalia (vista dorsal). d) Genitalia (vista ventral).

Fig 5.- Chelostoma edentulum $\sigma^{\pi}$. a) Antennal cleaning spur. b) $T_{7}$. c) Genitalia (dorsal view). d) Genitalia (ventral view).

negro, en su extremo; valvas peneanas regularmente adelgazadas desde su base al ápice, que es redondeado; en vista ventral, bordes internos paralelos entre la base y la zona media a partir de la cual convergen fuertemente hasta unirse (figs. $5 c, 5 d$ )

\section{Ch. (Chelostoma) edentulum}

\section{Subgénero Foveosmia (우 우)}

1. Clípeo con un diente medio triangular dispuesto verticalmente en la zona preapical. Antenas muy cortas. Cuerpo brillante con punteado fino y regular, con pilosidad corta y escasa de color pardo amarillento. Área horizontal del propodeo con finas y abundantes arrugas longitudinales, no separada de la vertical por una carena transversa. $T_{6}$ con setas espesas, pegadas, cortas $y$ amarillentas. Escopa de color amarillo blanquecino. Espolones tibiales amarillos. Longitud: $6-7 \mathrm{~mm}$

Ch. (Foveosmia) foveolatum

- Clípeo sin diente medio triangular en posición preapi- cal. Área horizontal del propodeo separada de la vertical por una carena transversa 2

2. Borde anterior del clípeo ligeramente redondeado. Mandíbulas cubiertas por una densa y larga pilosidad rojiza-amarillenta (fig. $8 \mathrm{a}$ ), la pubescencia más densa en el ápice y en el margen superior de la mandíbula. Ápice de la mandíbula más estrecho que su base; diente inferior unas 2-3 veces más largo que el mediano (fig. 8a). Área horizontal del propodeo más larga que el postescutelo (fig. 8b). Abdomen negro mate con tonos marrones, especialmente en los bordes de los segmentos. Escopa de color blanco amarillento. Longitud: 5-6 mm Ch. (Foveosmia) campanularum

- Borde anterior del clípeo solo ligeramente arqueado (fig. 10a). Mandíbulas con escasa pilosidad blanquecina. Ápice de la mandíbula no estrechado, más ancho que su base (fig. 10a); el diente inferior unas 3-4 veces más largo que el mediano. Cabeza estrecha, más larga que ancha, tan ancha como el tórax. Antenas claviformes (fig. 10b). Área horizontal del propodeo de igual 

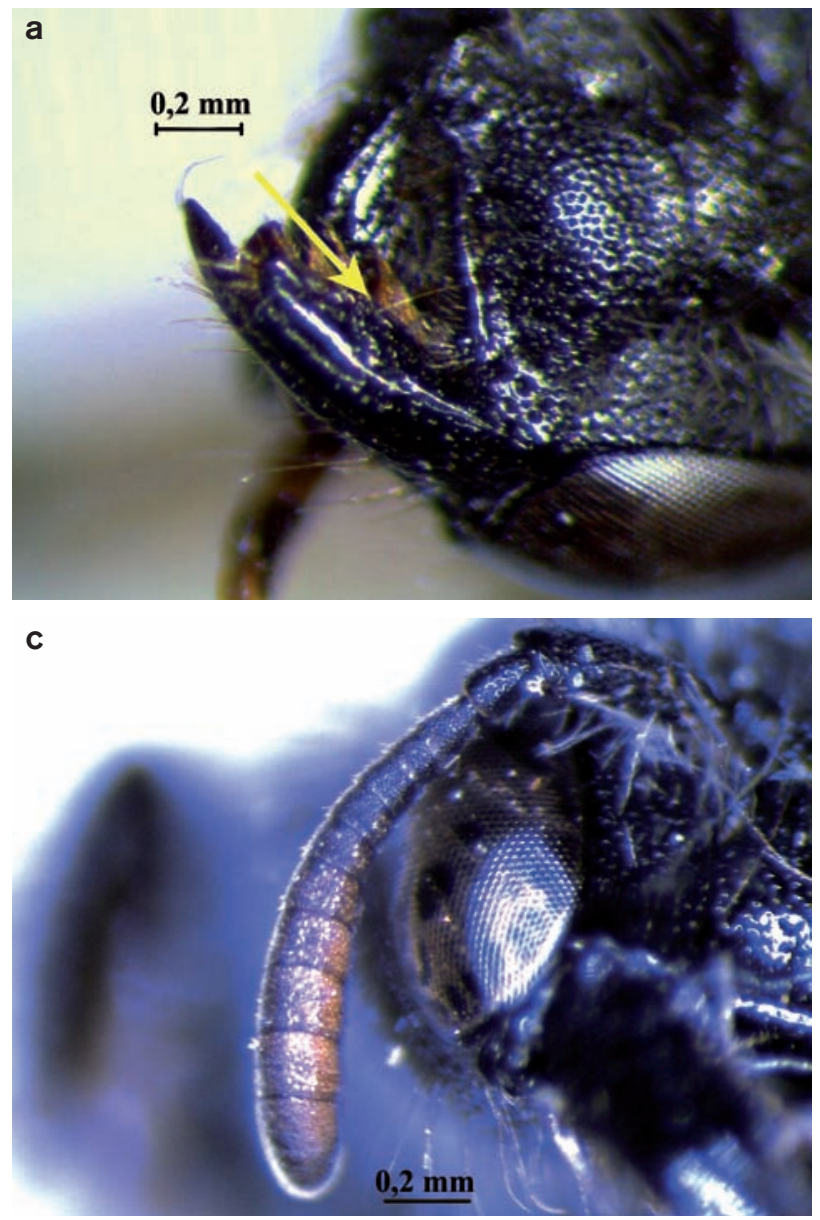

longitud o algo más corta que el postescutelo (fig. 10c); con arrugas longitudinales profundas y burdas, bordeada por elevaciones; área central lisa y brillante, con un profundo surco medio por debajo; a sus lados, el punteado es burdo y disperso. Escopa de color blanquecino a gris amarillento. Longitud: 5-6 mm

\section{Ch. (Foveosmia) distinctum}

\section{Subgénero Foveosmia $\left(\sigma^{x} \sigma^{x}\right)$}

1. Tórax con setas castaño amarillentas. Parte basal del área central con arrugas. Terguitos sin pilosidad llamativa. $T_{7}$ alargado, terminado en punta roma, no lobulado, con el ápice presentando lados paralelos y un hueco redondo en la base (fig. 12a). $E_{2}$ con una prolongación tubercular transversal en el centro (fig. 12b); $E_{5}$ apenas visible; $E_{6}$ con un profundo surco central. Longitud: 6-7 $\mathrm{mm}$................................. Ch. (Foveosmia) foveolatum

- $T_{7}$ estrechado en el ápice, con dos lóbulos apicales aplanados dorsoventralmente, apreciándose de forma triangular en vista lateral. $E_{2}$ con una prolongación tubercular transversal

2

2. Lóbulos de $T_{7}$ estrechos, con su margen externo recto; la hendidura entre ellos es unas dos veces tan ancha

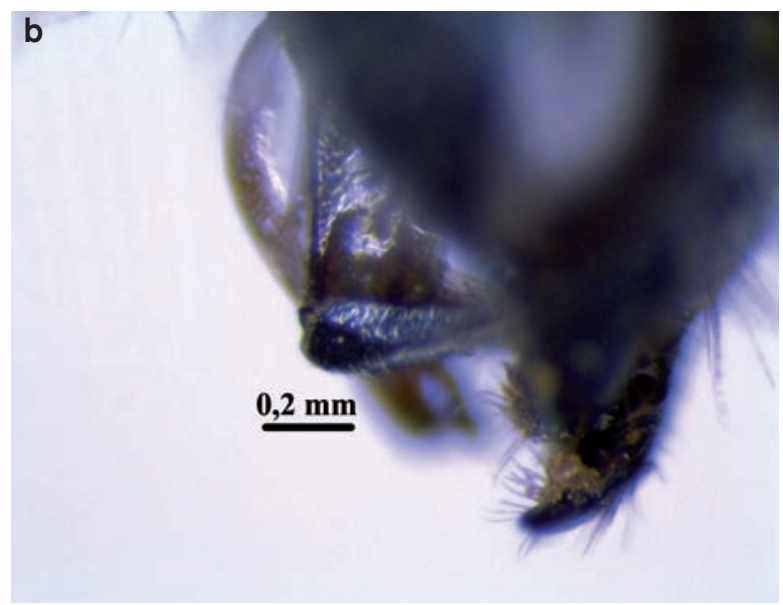

Fig 6.- Chelostoma emarginatum 오. a) Mandíbula. b) Labro (vista lateral). c) Antena.

Fig 6.- Chelostoma emarginatum $ᄋ$. a) Mandible. b) Labrum (lateral view). c) Antenna.

como la anchura de un lóbulo (fig. 9d). Área horizontal del propodeo más larga que el postescutelo (fig. 9a). $\mathrm{E}_{2}$ con un tubérculo transversal en su centro (fig. $9 \mathrm{~b}$ ). $\mathrm{E}_{4}$ en su borde posterior provisto de una franja de pestañas y una zona membranosa (fig. 9c). Longitud: 5-6 mm ........ Ch. (Foveosmia) campanularum

- Lóbulos de $T_{7}$ moderadamente estrechados, con sus bordes externos arqueados; la hendidura entre ellos es igual o más estrecha que la anchura de un lóbulo (fig. 11a). Área horizontal del propodeo tan larga o menor que el postescutelo (fig. $11 \mathrm{~b}$ ). $\mathrm{E}_{2}$ con un amplio tubérculo transversal en su centro (fig. 11c). Borde posterior de $E_{5}$ con una franja de setas largas gris-amarillentas que cubren al menos la mitad de $\mathrm{E}_{6}$ (fig. 11d). Longitud: 5-6 $\mathrm{mm}$ Ch. (Foveosmia) distinctum

\section{Subgénero Gyrodromella ( 우 우)}

1. Clípeo (fig. 13a) fuertemente convexo en el centro, con punteado denso y burdo; borde anterior con pequeños dientes pronunciados, separados. Vértex con carena preoccipital (fig. 13b). Área horizontal del propodeo sin carena y más corta que el postescutelo (fig. 13c). Mesonoto con punteado brillante, burdo y espeso. 

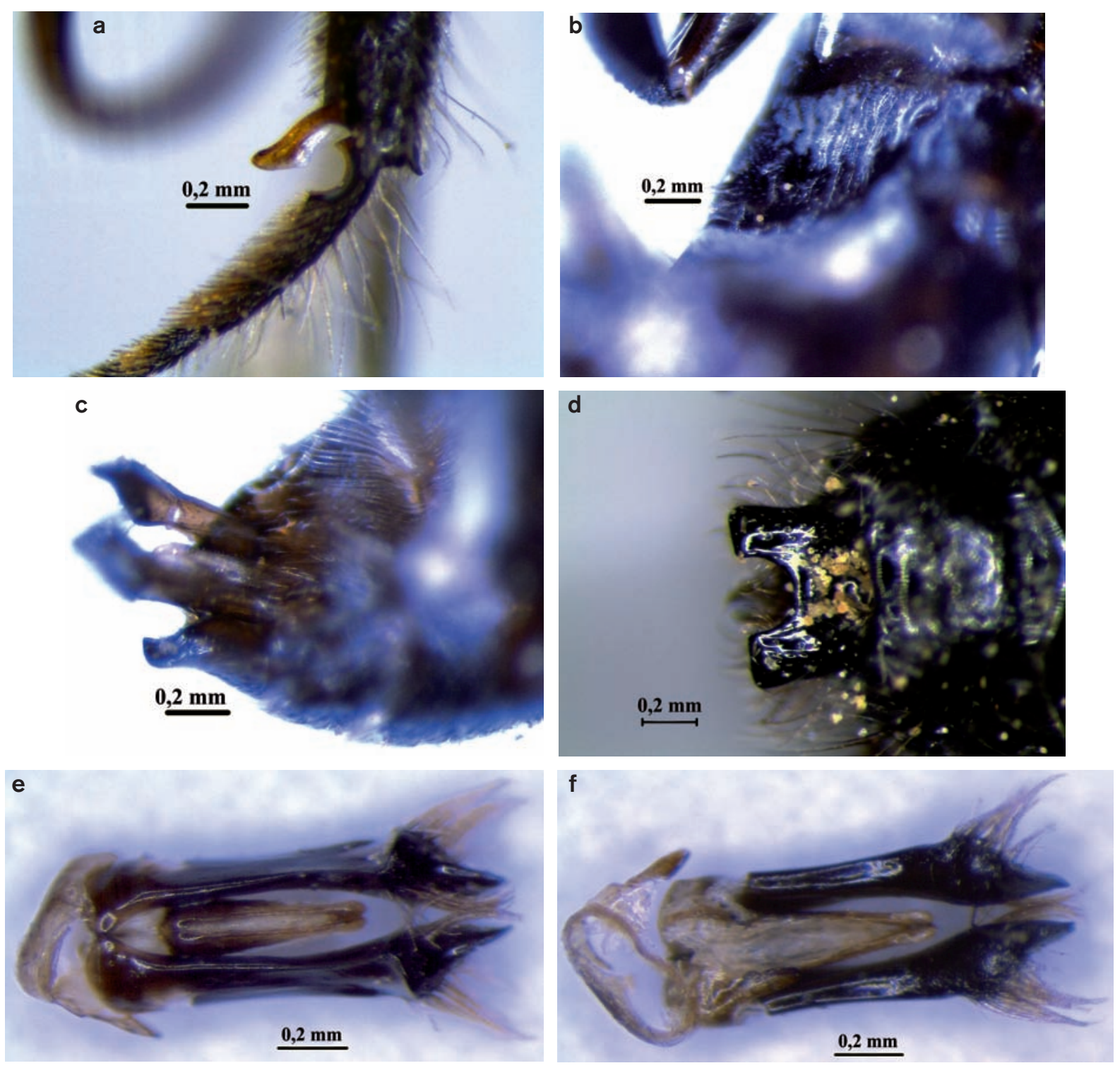

Fig 7.- Chelostoma emarginatum $\sigma^{\pi}$. a) Espolón limpiador antenal. b) $E_{3}$. c) $E_{5}$. d) $T_{7}$. e) Genitalia (vista dorsal). f) Genitalia (vista ventral).

Fig 7.- Chelostoma emarginatum $\sigma^{\pi}$. a) Antennal cleaning spur. b) $E_{3}$. c) $E_{5}$. d) $T_{7}$. e) Genitalia (dorsal view). f) Genitalia (ventral view).

Escopa blanco amarillenta. Longitud: 8-9 mm Ch. (Gyrodromella) rapunculi

- Cabeza muy alargada, comprimida. Clípeo convexo inclinándose hacia el extremo anterior en forma de media luna (fig. 15a); punteado grueso y disperso, disminuyendo en el disco, muy brillante al igual que la zona supraclipear interantenal; borde anterior con dientes poco aparentes. Vértex sin carena preoccipital. Área horizontal del propodeo (fig. 15b) más corta que el postescutelo, con un fina carena separándola de la parte inclinada.
Longitud: 8-9 mm

Ch. (Gyrodromella) nasutum

\section{Subgénero Gyrodromella $\left(\sigma^{7} \sigma^{7}\right)$}

1. Vértex con carena preoccipital (fig. 14a). $T_{7}$ ensanchado transversalmente y trilobulado apicalmente formando tres láminas anchas y romas (fig. 14b); los dos lóbulos laterales situados por encima del lóbulo mediano. 


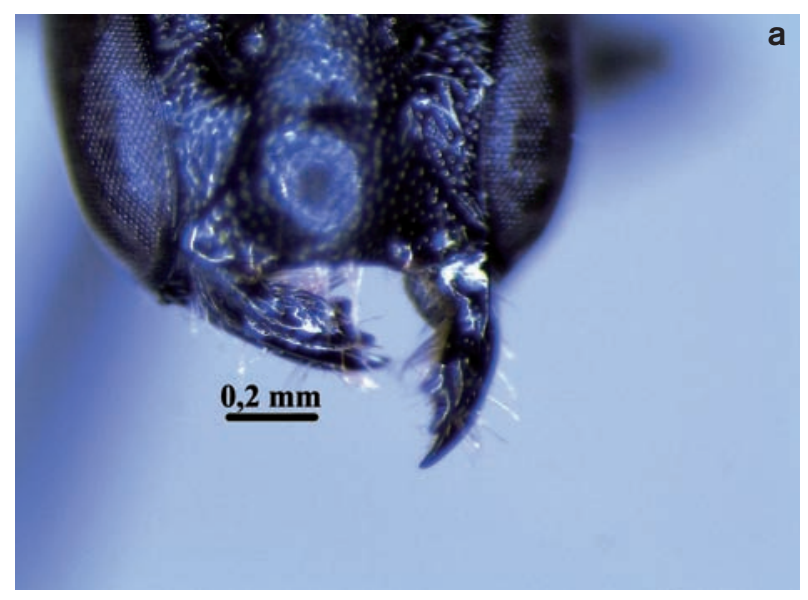

b

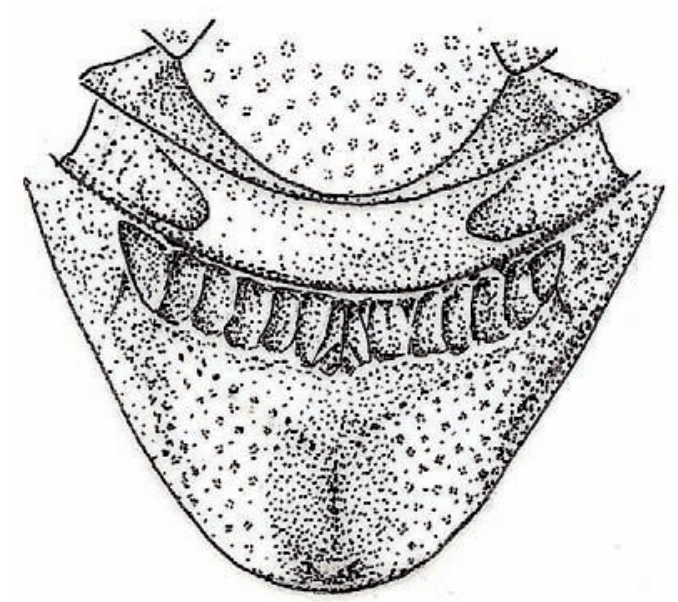

Fig. 8.- Chelostoma campanularum ㅇ․ a) Mandíbulas. b) Propodeo (área horizontal).

Fig. 8.- Chelostoma campanularum 오 a) Mandibles. b) Propodeum (horizontal area).

Extremo apical de los terguitos con bandas de setas apenas marcadas. Proyección de $\mathrm{E}_{2}$ con la sección transversal semicircular y aplanada, con el borde adelgazado-afilado y una pendiente pronunciada hacia la base del esternito (fig. 14c); $\mathrm{E}_{3}$ cóncavo y delimitado a cada lado por una elevación cubierta de gruesas setas negras; $E_{4}$ con dos láminas membranosas de color pálido en su extremo; $E_{5}$ cubierto en su mayor parte por una pestaña de setas amarillentas largas y onduladas (fig. 14d). Longitud: 9-11 mm

Ch. (Gyrodromella) rapunculi

- Vértex sin carena preoccipital. $\mathrm{T}_{7}$ ancho y bilobulado; lóbulos divergentes y de bordes paralelos (fig. 16a). Extremo apical de los terguitos con manchas de setas blanquecinas a los lados. Tubérculo de $\mathrm{E}_{2}$ con la sección transversal semicircular y aplanada, con el borde adelgazado-afilado y una pendiente pronunciada hacia la base del esternito (fig. 16b); $E_{3}$ cóncavo; $E_{4}$ sin láminas membranosas en su extremo; $E_{5}$ densamente punteado y con una pestaña de setas rojizas largas y onduladas (fig. 16c). Longitud: 9-10 mm

Ch. (Gyrodromella) nasutum

DisTRIBUCIÓN Y DATOS NUEVOS DE LAS ESPECIES IBÉRICAS DEL GÉNERO CHELOSTOMA

Se trata de un género de abejas con distribución holártica y oriental: Norteamérica, Eurasia, norte de África y noreste de la India, Myanmar y Tailandia (Michener, 2007). Según este autor, existen 3 subgéneros en el territorio estudiado.

Graellsia, 68(2), Diciembre 2012, pp. 263-280 - ISSN: 0367-5041

doi:10.3989/graellsia.2012.v68.058
Subgénero Chelostoma Latreille, 1809

Distribución paleártica, aunque ha sido introducido en el estado de Nueva York, EE.UU. (Michener, 2007).

\section{Chelostoma (Chelostoma) edentulum Pérez, 1895}

Especie conocida del norte de África (Ornosa et al., 2006) y citada recientemente en el sur de Europa, en España, en las provincias de Almería y Granada, y en Portugal, en el distrito de Beja (OrtizSánchez et al., 2008). Los registros actuales amplían la distribución ibérica conocida de la especie.

Nuevos Registros: Espana: Cáceres: Portaje, 15-V-1999, $10^{\pi}$; 30-VI-1999, $10^{\top}$; Gayubo et al. leg., USAL. Córdoba: El Soldado, 23-IV-1927, $10^{7}, 1$ ㅇ ; 9-V-1927, $10^{7}$; 28-VI-1927, $1 \sigma^{\top} ; 1$ ㅇ , $3 \sigma^{\top} \sigma^{\top}$, Seyrig leg., MNCN. Madrid: El Pardo, 2 우 우, J. Gil leg.; 08-V-1920, 13 우 우, $210^{\top} \sigma^{\pi}$, Dusmet leg.; Madrid, 18-V-1923, 1 우, Dusmet leg.; 8-VI-1906, 1 우, A. Sanz leg.; Pozuelo, 10', La Fuente leg., MNCN. Sevilla: Sevilla, abril, $10^{\pi}, \mathrm{MNCN}$.

Chelostoma (Chelostoma) emarginatum (Nylander, 1856)

Especie repartida por Europa meridional y central, Transcáucaso y norte de África (Ornosa et al., 2006). Conocida en el territorio ibérico por citas antiguas recogidas por Ceballos (1956) de localidades de las provincias de Barcelona y Gerona, de 

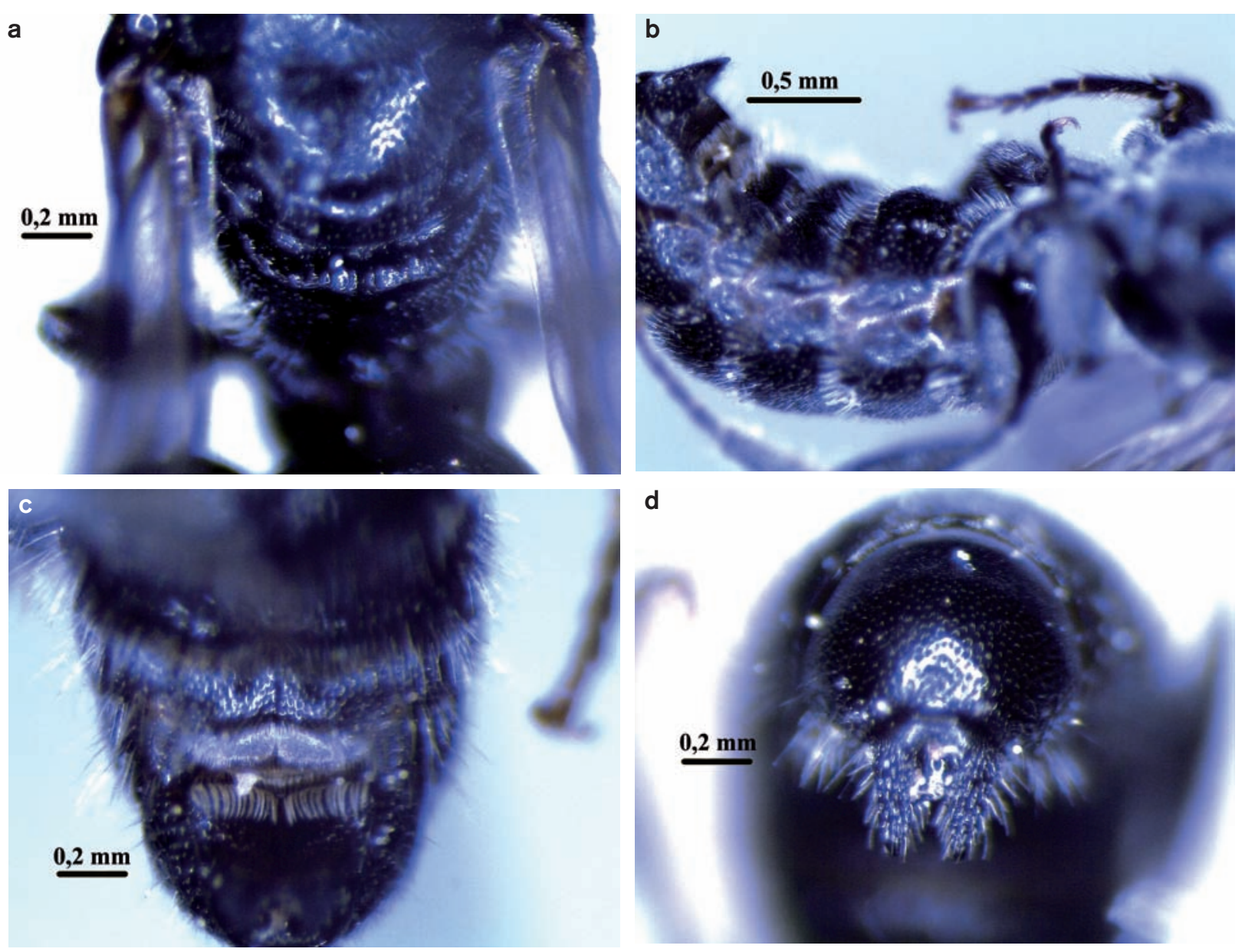

Fig. 9.- Chelostoma campanularum $\sigma^{\top}$. a) Propodeo (área horizontal). b) $E_{2}$. c) $E_{4}$. d) $T_{7}$.

Fig. 9.- Chelostoma campanularum $\sigma^{\pi}$. a) Propodeum (horizontal area). b) $E_{2}$. c) $E_{4}$. d) $T_{7}$.

Almería (Ortiz-Sánchez, 1992), y Coimbra, Figueira da Foz, Motemor-o-Velho y Serra da Estrela en Portugal (Diniz, 1989). Los registros actuales amplían su distribución conocida en España.

Nuevos Registros: Espana: Almería: Dalías, 300m, 30SWF1373, 19-III-1991, 1 \& , F.J. Ortiz-Sánchez leg., FJOS. Barcelona: Les Planes Vallvidrera, Sarriá-Sant Gervasi, V-1924, 2 우 우, Farriols leg.; Vallvidrera, Sarriá-Sant Gervasi, 14-IV-1897, 1 ㅇ , André leg., MNCN. Córdoba: El Soldado, $10^{\top}$, Seyrig leg., MNCN. Madrid: Escorial, $10^{\pi}$, Dusmet leg., MNCN. Valladolid: R.N. Castronuño, huerto, 1-15-V-2007, 12 우 우, $50^{7} \sigma^{7}$; R.N. Castronuño, El Gurugu, jaral, 16-31-V2007, 1 우; 1-15-VI-2007, 1 우; R.N. Castronuño, Pollos, bosque de ribera, 16-31-V-2007, 1 우 ; 1-15-V-2007, 3 우우; R.N. Castronuño, Arenales de El Villar, 1-15-V-2007, 1 웅 R.N. Castronuño, La Rinconada, pinar, 1-15-V-2007, 1 \& ; R.N. Castronuño, Dehesa de Cubillas, monte, 1-15-VI-2007, 1 우 ; R.N. Castronuño, Casas de Bayona, pinar, 16-30-VI-
2007, 1 ㅇ, Gayubo et al. leg., USAL. Zaragoza: Pina de Ebro, 17-III-1990, $10^{7}$; 14-IV-1990, $10^{\top}$; 9-IV-1991, $40^{7} \sigma^{7} ; 25-I V-$

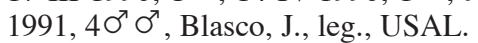

Chelostoma (Chelostoma) florisomne (Linnaeus, 1758)

Especie distribuida desde España en el sur, por toda Europa -excepto la zona más septentrionalCáucaso y norte de África (Ornosa et al., 2006). En el territorio ibérico, hasta ahora, se había registrado en las provincias de Barcelona y Madrid en España (Ceballos, 1956; Pérez-Iñigo, 1984) y Aveiro, Coimbra, Leça da Palmeira y Lousã en Portugal (Diniz, 1989). Los registros actuales extienden su distribución conocida. 

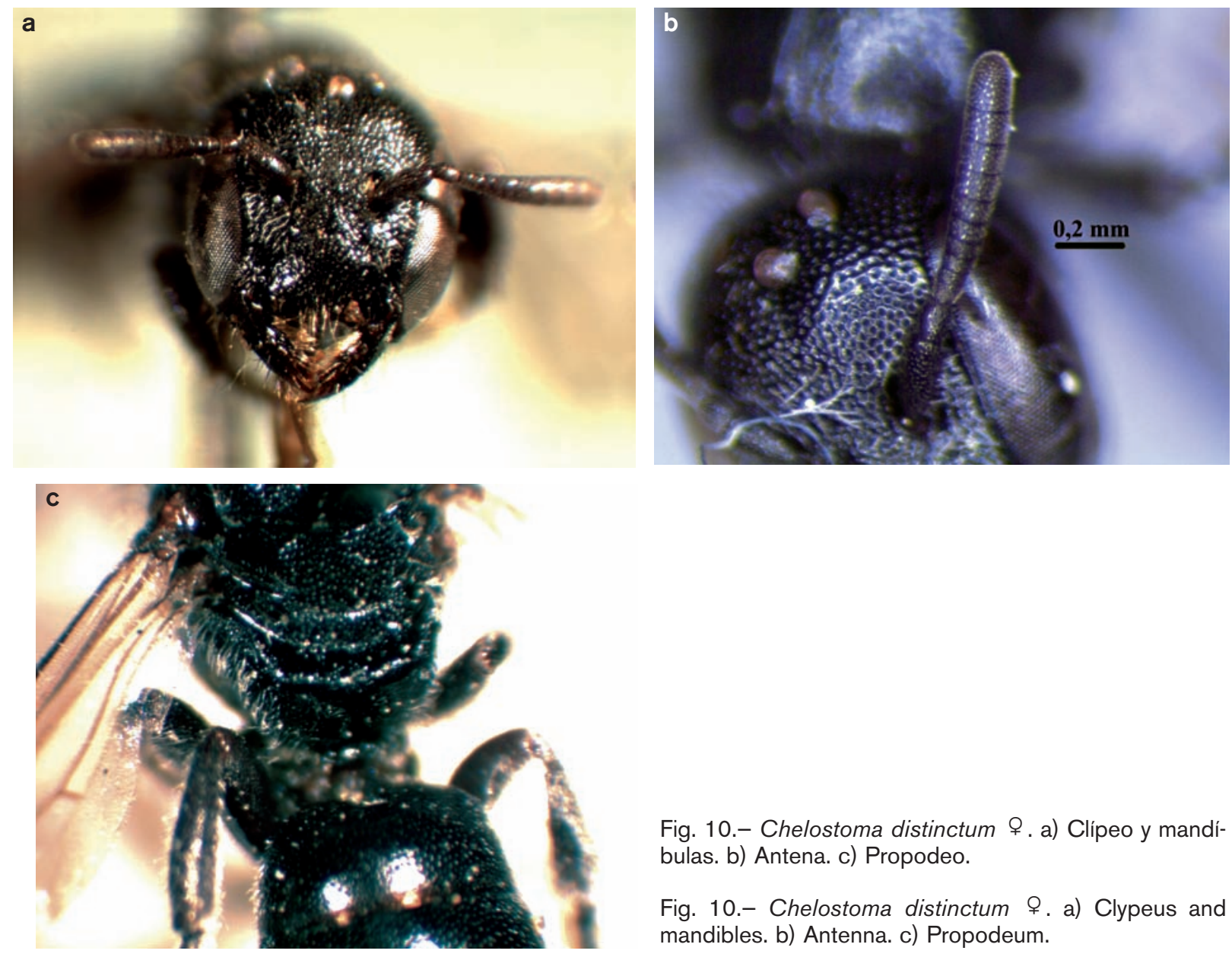

Fig. 10.- Chelostoma distinctum 오 a) Clípeo y mandíbulas. b) Antena. c) Propodeo.

Fig. 10.- Chelostoma distinctum 오 a) Clypeus and mandibles. b) Antenna. c) Propodeum.

Nuevos Registros: Espana: Ávila: Candeleda, V-1941, $10^{7}$, Escalera leg., MNCN. Cáceres: Portaje, 15-IV-1999, 4 우 우; 15-III-2003, 10; 1-IV-2003, 1 우; Gayubo et al. leg., USAL. Ciudad Real: Ruidera, 2 우 $\uparrow$, La Fuente leg., MNCN. Córdoba: El Soldado, 1 ㅇ, Seyrig leg., MNCN. Granada: Cenes de la Vega, 30SVG5913, 14-V-1983, 1 오․ A. Madero leg., FJOS; El Vadillo, Sierra Nevada, 15-V-1982, $10^{7}$, A. Tinaut leg., FJOS; Fuente del Avellano, Granada, $770 \mathrm{~m}$, 30SVG6415, 21-IV-1984, 1 ㅇ , C. Plaza leg., FJOS; ídem, 2-V1984, $10^{\pi}$, C. Plaza leg., FJOS; Hotel del Duque [GüiéjarSierra], Sierra Nevada, 20-V-1986, 30SVG6510, 2 우 우, F.J. Ortiz-Sánchez leg., FJOS; La Hortichuela, Güéjar-Sierra, Sierra Nevada, 8-V-1983, 1 오, FJOS; río Darro, Granada, 30SVG5115, 1-V-1987, 1 우, F.J. Ortiz-Sánchez leg., FJOS; [río] San Juan, Sierra Nevada, 14-V-1983, A. Tinaut leg., FJOS. Huesca: V. de Ordesa, 2 우 으, Dusmet leg., MNCN. Jaén: Vadillo de Castril, Sierra de Cazorla, V-1953, A. Cobos leg., EEZA. Madrid: El Pardo, 5 우 우, $70^{7} 0^{7}$, Dusmet leg., MNCN; El Ventorrillo, 1480 m, 23-31-V-1990, 1 ㅇ, Nieves y Rey leg., USAL; Madrid, $1 \sigma^{\pi}$, Mercet leg., MNCN; Miraflores, $10^{\pi}$, MNCN; Paular, Rascafría, 1\%, MNCN; Sierra de Guadarrama, 10 , Dusmet leg., MNCN. Salamanca: Santa María de Sando, 31-V-2002, 1 우; 30-IV-2002, $10^{7}$; Gayubo et al. leg., USAL. Segovia?: Ortigosa, VI-1902, 1 우, VII-1902, 1 우, MNCN.

\section{Subgénero Foveosmia Warncke, 1991}

Subgénero establecido por Warncke (1991) dentro del género Osmia, para incluir especies de pequeño tamaño.

\section{Chelostoma (Foveosmia) campanularum (Kirby, 1802)}

Especie distribuida, desde España en el sur, por toda Europa, excepto en las latitudes más altas del norte; una referencia antigua (Maidl, 1922) de Argelia no parece haberse repetido posteriormente (Ornosa et al., 2006); no obstante, Müller (2012) mantiene esta cita como válida. En el territorio considerado se conocía de las provincias de Cuenca, Gerona, Huesca y León y de Madrid en España (Pérez-Íñigo, 1984), así como de Aveiro, Coimbra, Sintra, Viseu y Vouzela en Portugal (Diniz, 1989). Los registros actuales amplían su distribución ibérica conocida. 

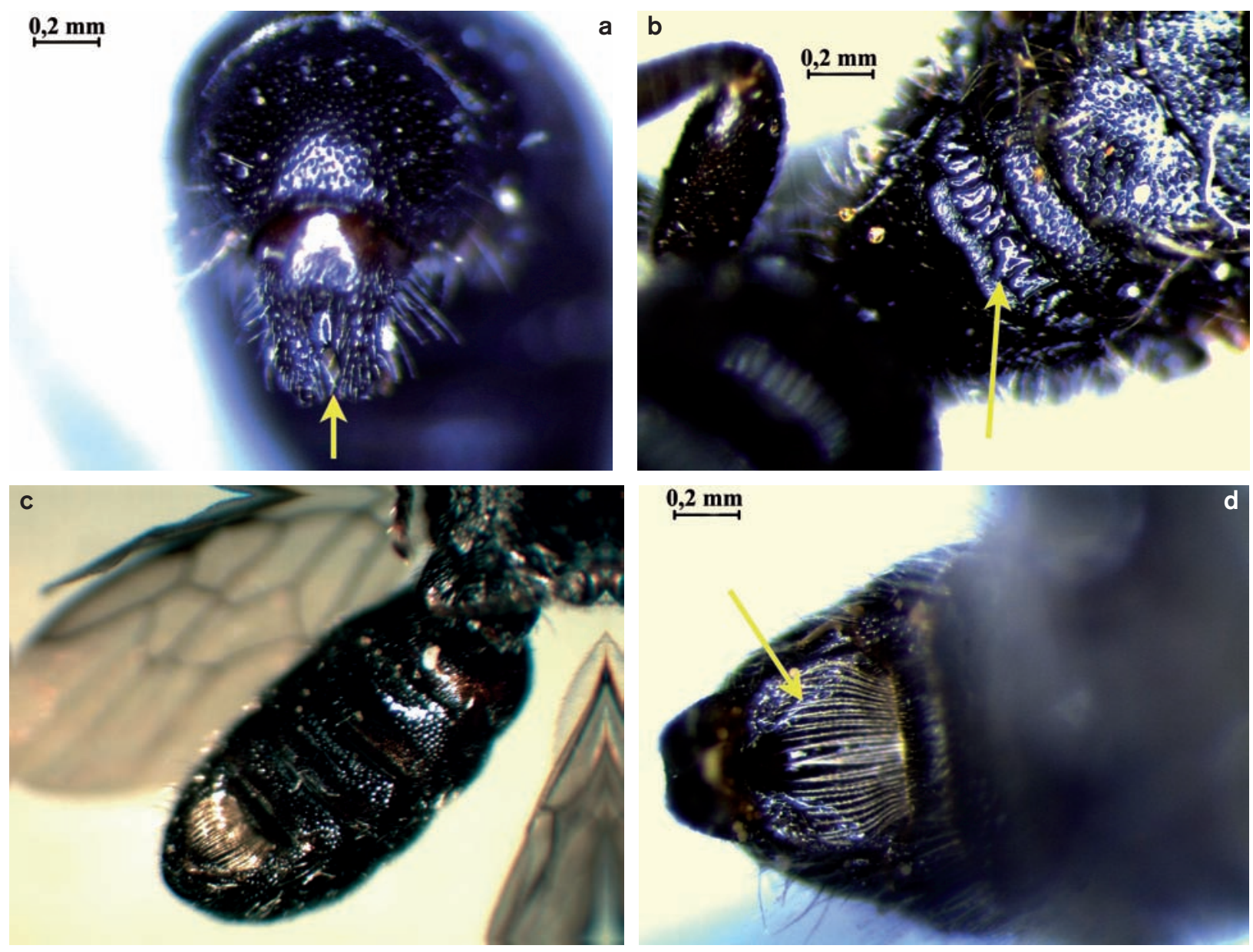

Fig. 11.- Chelostoma distinctum $\sigma^{\top}$. a) $T_{7}$. b) Propodeo (área horizontal). c) $E_{2}-E_{5}$. d) $E_{5}$.

Fig. 11.- Chelostoma distinctum $\sigma^{x}$. a) $T_{7}$. b) Propodeum (horizontal area). c) $E_{2}-E_{5}$. d) $E_{5}$.

Nuevos REgISTROS: Espana: Asturias: La Bobia, 23-VII2006, $10^{7}$, F. Torres leg., USAL. Burgos: Villaverde del Monte, 31-V-1999, $10^{7} ; 15-31-V-2003,4$ 우 운, $4 \sigma^{7} \sigma^{7} ; 1-15-V I-2003$,

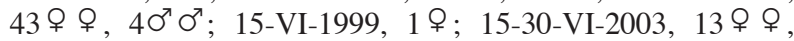
$50^{\top} 0^{\top}$; 30-VI-1999, 16 우 우, $20^{7} 0^{\top}$; Gayubo et al. leg., USAL. Cáceres: Torrecilla de los Ángeles, 21-VII-1987, $10^{7}$, F. Torres leg., USAL; Portaje, 15-IV-1999, 2 우 우 ; 30-IV-1999, 3 우 우, $10^{\circ}$; 15-V-1999, 10 우 우, $30^{7} \sigma^{7}$; Gayubo et al. leg., USAL. Ciudad Real: Pozuelo de Calatrava, 10 $0^{7}$, La Fuente leg., MNCN. Cuenca: El Hosquillo, 15-VI-1974, $10^{\pi}$, C.P. Íñigo leg., UCM. Gerona: Camprodón, 13-VIII-1898, 1 ㅇ ; 14-VIII1898, 1 우 ; VII-1919, $2 \sigma^{7} \sigma^{7}$; VII-1920, $10^{7}$; VII-1921, $1 \sigma^{7}$, Dusmet leg., MNCN; San Juan de las Abadesas, 22-VII-1928, $10^{7}$, MNCN. Granada: Iznalloz, 30SVG4937, 9-V-1987, $10^{7}$, F.J. Ortiz-Sánchez leg., FJOS; Sierra Nevada, VI-1926, $10^{\sigma}$, Dusmet leg., MNCN; Soportújar, 29-VI-1983, $10^{7}$, A. Cobos leg., EEZA. Huesca: Candanchú, Canfranc, 1 ㅇ , Dusmet leg., MNCN. Madrid: El Ventorrillo, 1480 m, 1-8-VII-1988, $10^{\text {", }}$ 13-17-VII-1988, $10^{7}$; 14-25-VII-1988, 4 우 우, $20^{7} \sigma^{7}$; 17-21-
VII-1988, 2 우 우, $10^{7}$; 9-14-VII-1988, 2 우 우, $20^{x} \sigma^{x} ; 1$-9-VIII1988, 1 우 ; 31-VI-6-VII-1989, 1 우; 22-30-VI-1989, 2 우 우; 14 VII-1989, 1 우; 23-31-V-1990, $20^{7} \sigma^{7} ; 1-6-V I-1990,1$ 우, $10^{7}$; Nieves y Rey leg., USAL; El Pardo, El Goloso, 24-31-V-1991, $10^{\top}$, Nieves y Rey leg., USAL; Escorial, 1 ㅇ, Dusmet leg., MNCN; Madrid, $10^{\pi}$, Mercet leg., MNCN; 7 우 우, MNCN; Prov. Madrid, $10^{\top}$, Chauffer leg., MNCN. Palencia: Nogales de Pisuerga, 10-VII-1987, $10^{7}$, A. Rueda leg., USAL. Salamanca: Poblado Saucelle, 23-V-1998, 5 우 우, $80^{7} 0^{7}$; Saucelle, 12-V-1997, 3 ㅇ 우, 25-V-1997, 3 우 우 ; 22-VI-1997,

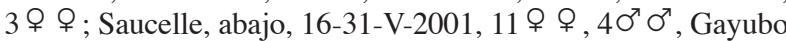
et al. leg.; 1-15-VI-2001, 19 우 우, 40 $0^{\top} \sigma^{\top}$; 16-30-VI-2001, 9 우 우, 10; ; Saucelle, arriba, 16-31-V-2001, 3 우 우, Salto Saucelle, 22-VI-1996, $10^{7}$; 8-VI-1996, 1 ㅇ ; 26-IV-1997,

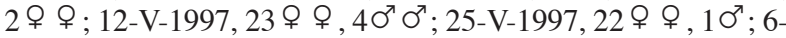
VI-1997, 8 우 우; 8-VI-1997, 4 우 우, $10^{7} ; 12-\mathrm{VI}-1997,10^{7} ; 22-$ VI-1997, 14 우 우; 6-VII-1997, 6 우 \$; 8-VII-1997, $10^{7}$; 6-V-1998, $10^{7}$; 18-VII-1998, 1 우; 1-15-V-1998, 2 우 우; 16-31- 


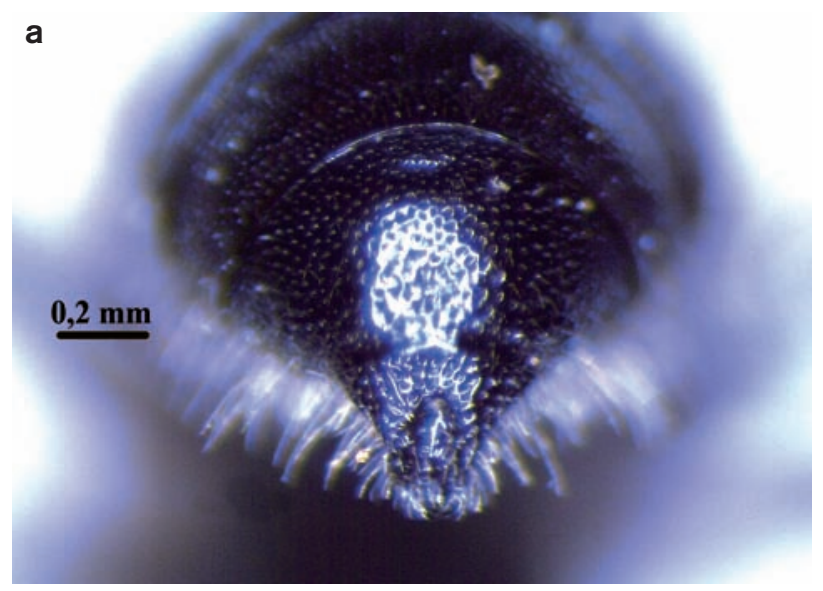

Fig. 12.- Chelostoma foveolatum $\sigma^{\pi}$. a) $T_{7}$. b) $E_{2}$.

Fig. 12.- Chelostoma foveolatum $\sigma^{\pi}$. a) $T_{7}$. b) $E_{2}$.

V-1998, 1 우, 107; 1-15-VI-1998, 6 우 우, $20^{7} \sigma^{7} ;$ 6-VI-1998, 3 우 우, $10^{\pi}$; 16-30-VI-1998, 2 우 우, $10^{\top} ;$ 20-VI-1998, 9 우 우,

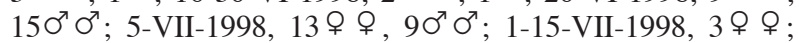
16-31-VII-1998, 1 ㅇ ; 18-VII-1998, 1 ㅇ ; 15-VIII-1998, $10^{0}$; 16-30-VI-2001, 1 ㅇ ; Gayubo et al. leg., USAL; Aldeadávila, 8VI-1997, 1 우; 22-VI-1997, 2 우 우 ; 20-VII-1997, 2 우 우; Gayubo et al. leg., USAL; Salto Aldeadávila, 6-VI-1998, $10^{\text {厂’, }}$ 23-V-1998, 1 ㅇ; $20-$ VI-1998, 4 우우 ; 18-VII-1998, 2 우 우; Gayubo et al. leg., USAL; Santa María de Sando, 31-V-2002, 3 우 우, $10^{7}$; 15-V-2002, 2 우 우; 15-VI-2002, 13 우 우; 30-VI2002, 1 우 ; 16-31-V-2003, 1 우; 1-15-VI-2003, 1 우 ; Gayubo et al. leg., USAL; Villarino, 8-VI-1996, 2 우 우; 22-VI-1996, 1 우; Gayubo et al. leg., USAL; San Martín del Castañar, 15-VI1999, 3 우 우; 31-V-1999, 2 우 우; Gayubo et al. leg., USAL. Soria: Tardajos de Duero, 11-VII-1989, 10", J. García leg., USAL. Toledo: Paredes de Escalona, 31-V-1999, 3 우 우, $10^{\circ}$; 15-V-1999, $20^{7} \sigma^{7}$; 15-VI-1999, 4 우 우; 15-IV-2003, 2 우 우; 15V-2003, $40^{7} \sigma^{\top} ; 1-\mathrm{VI}-2003,14$ 우 우; 16-30-VI-2003, 1 ㅇ ; Gayubo et al. leg., USAL. Valladolid: R.N. Castronuño, Arenales de El Villar, 1-15-VI-2007, 1 ㅇ ; R.N. Castronuño, Casas de Bayona, pinar, 1-15-VI-2007, 5 우 우 ; 16-30-VI-2007, 8 우 ; 1-15-VII-2007, 2 우 우; R.N. Castronuño, Casa Don Mauro, pinar, 1-15-VI-2007, 2 우 우 ; R.N. Castronuño, Dehesa de las Cubillas, monte, 1-15-VII-2007, 2 우; R.N. Castronuño, huerto, 1-15-VII-2007, 1 ㅇ ; 16-30-VI-2007, 1 우 ; R.N. Castronuño, La Rinconada, encinar, 16-31-V-2007, 1 우; R.N. Castronuño, Los Pocitos, encinar, 1-15-VI-2007, 1 ㅇ ; R.N. Castronuño, Los Pocitos, límite de duna, 1-15-VI-2007, 1 ㅇ ; 16-30-VI-2007, 1 우 ; Gayubo et al. leg., USAL. Vizcaya: Zaldívar, $10^{7}$, Dusmet leg., MNCN. Zamora: Cabañas de Aliste, 1-15-VI-2000, 1 우, Gayubo et al. leg., USAL.

Portugal: Covão da Ametade, 24-VII-1987, $2 \sigma^{7} \sigma^{7}$, F. Torres leg., USAL; Cabeça, 25-VII-1987, $10^{7}$, F. Torres leg., USAL; P. N. do Douro Internacional: Mazouco, 2001, 5 ㅇ $\%, 2 \sigma^{7} \sigma^{7}$; Fonte de Aldeia, 2001, 10 우 우, $60^{7} \sigma^{7}$; Bemposta, 2001, 1 오; Lamoso, 2001, 1 우; Algozinho, 2001, 1 우; To, 2001, 3 우 우; Figois, 2001, 4 우, N.G. Olivera leg., USAL.

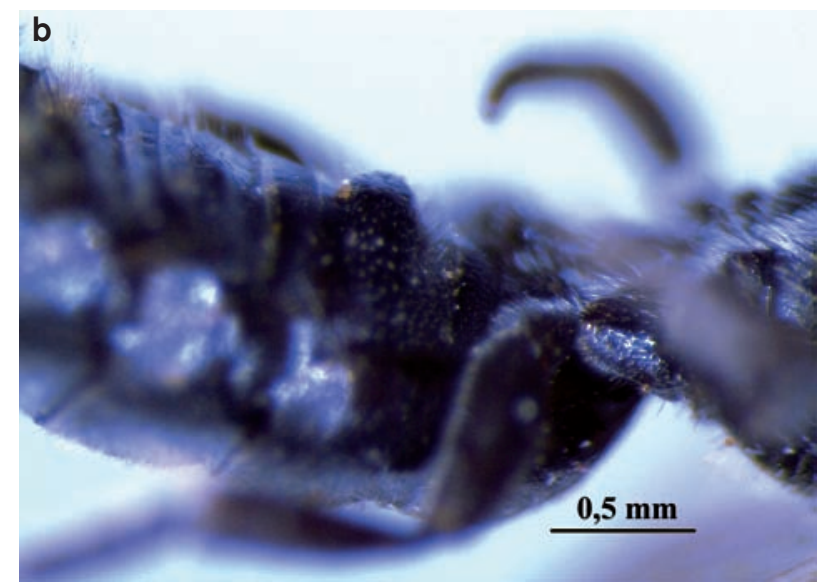

Chelostoma (Foveosmia) distinctum (Stöckhert, 1929)

Distribución europea hasta la Península Balcánica (Ornosa et al., 2006). En España se conoce exclusivamente por una cita de Cantabria (Ceballos, 1956), referenciada luego por otros autores.

Nuevos Registros: Espana: Barcelona: Les Planes Vallvidrera, Sarriá-Sant Gervasi, V-1924, $20^{7} \sigma^{7}$, Farriols leg., MNCN. Mallorca: Pollensa ?, 26-VIII-1916, 1 के , Enslin leg., MNCN.

\section{Chelostoma (Foveosmia) foveolatum (Morawitz, 1868)}

Especie con distribución por Europa, zonas cálidas del centro y sur del continente, incluido el territorio mediterráneo septentrional desde España, hasta Turquía (Ornosa et al., 2006). En la fauna ibérica se conocía hasta ahora en la provincia de Madrid en España (Pérez-Íñigo, 1984) y de Aveiro, Coimbra y Gouveia en Portugal (Diniz, 1989), de modo que el registro actual amplía su distribución conocida.

NuEvoS REGISTROS: Espana: Burgos: Villaverde del Monte, 30-VI-1999, $10^{\text {T }}$, Gayubo et al. leg., USAL. Huesca: Biescas, 9-VII-2009, $10^{7}$, C. Ornosa leg., UCM. Lérida: Desfiladero de Collegats, 07-VII-2009, $10^{7}$, F. Torres leg., UCM.

\section{Chelostoma (Foveosmia) ventrale Schletterer, 1889}

Especie mediterránea occidental que llega hasta Turquía, referenciada del norte de África y citada, en Europa meridional, de los Pirineos orientales y Eslovenia, y en España solo en Madrid, por Pérez- 

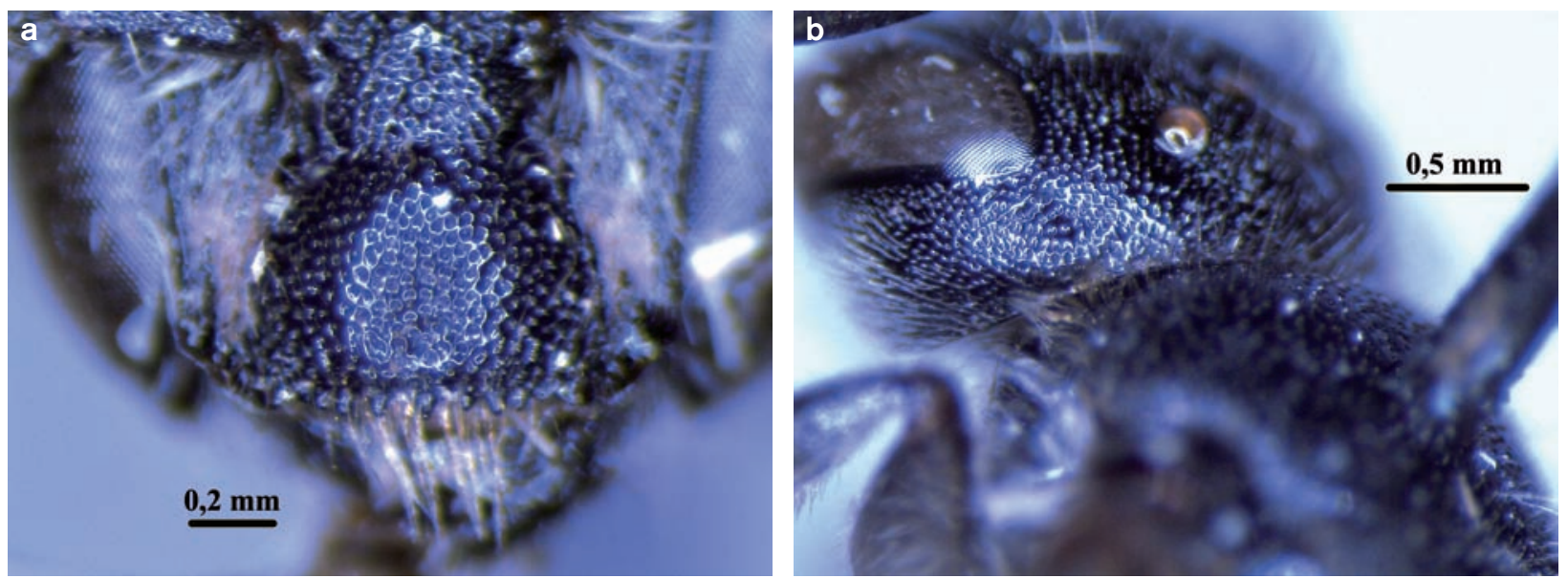

Fig. 13.- Chelostoma rapunculi ㅇ․ a) Clípeo. b) Carena preoccipital. c) Propodeo (área horizontal).

Fig. 13.- Chelostoma rapunculi ㅇ․ . a) Clypeus. b) Preoccipital carina. c) Propodeum (horizontal area),

Íñigo (1984) (Ornosa et al., 2006). La cita de Madrid se ha confirmado como errónea (Müller, 2012) y se considera que esta especie no se encuentra presente en la Península Ibérica.

Subgénero Gyrodromella Michener, 1997

Subgénero de distribución paleártica, mejor conocido en Europa central y septentrional, de acuerdo con Griswold \& Michener (1998) y Michener (1997, 2007), autor este que le asignaba alrededor de 6 especies.

\section{Chelostoma (Gyrodromella) nasutum Pérez, 1895}

Especie del norte de África (Ornosa et al., 2006) y Europa central y septentrional (Ungricht et al., 2008). Ungricht et al. (2008) y Müller (2012) mencionan su presencia en España, sin más datos.

NuEvos REGISTROS: No se aportan nuevos registros para esta especie.

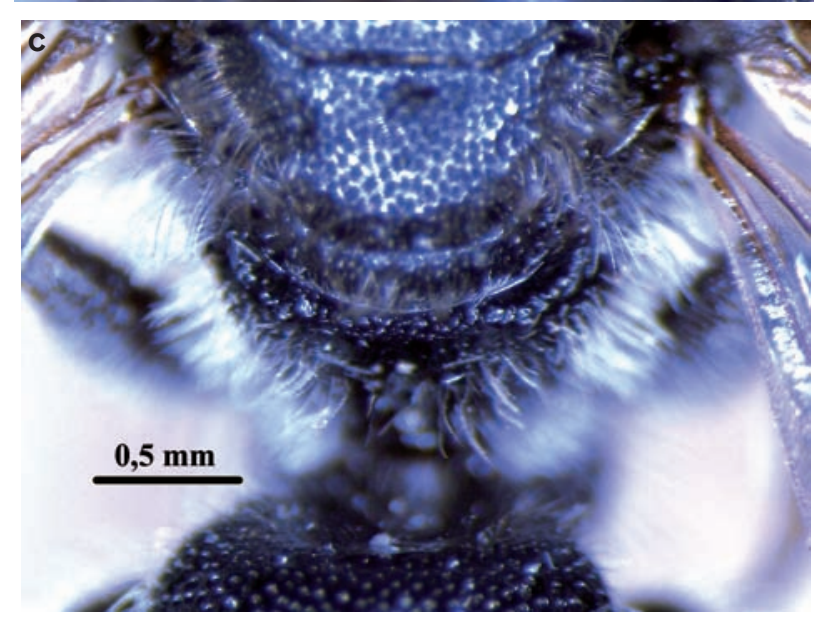

Chelostoma (Gyrodromella) rapunculi (Lepeletier, 1841)

Especie distribuida por el centro y el norte de Europa, incluida Siberia, por Francia, en el norte montañoso y en los Alpes; más rara en Europa meridional y Asia Menor, pero citada en Marruecos y España (Bofill, 1905; Ceballos, 1956; Pérez-Íñigo, 1984; Ornosa et al., 2006). En la Penísula Ibérica fue citada de Cataluña y Madrid (Pérez-Íñigo, 1984), si bien la primera de ellas parece ser un error de transcripción desde el catálogo de Ceballos (1956), y de Amarante, Angeiras, Coimbra, Leça da Palmeira y Oliveira do Barro en Portugal (Diniz, 1989). Los registros actuales constituyen, por lo tanto, interesantes nuevas citas para el territorio ibérico.

Nuevos Registros: Espana: Almería: Arroyo Anchuelo, Sierra Nevada, Bayárcal, 1550 m, 30SWG0001, 4-VII-1993, $10^{\pi}$, F.J. Ortiz-Sánchez leg., FJOS. Ávila: Parador de Gredos, VII-1930, $10^{7}$, Dusmet leg., MNCN. Barcelona: Sant Feliu de Llobregat, 26-V-1924, $10^{7}$, Mas de Xaxars leg., MNCN. Burgos: Piedra?, 10", Dusmet leg., MNCN; Villaverde del Monte, 15-31-V-2003, $10^{7}, 1-15-$ VI-2003, $10^{7}$; 30-VI-1999, $10^{\pi}$; Gayubo et al. leg., USAL. Ciudad Real: Pozuelo de 

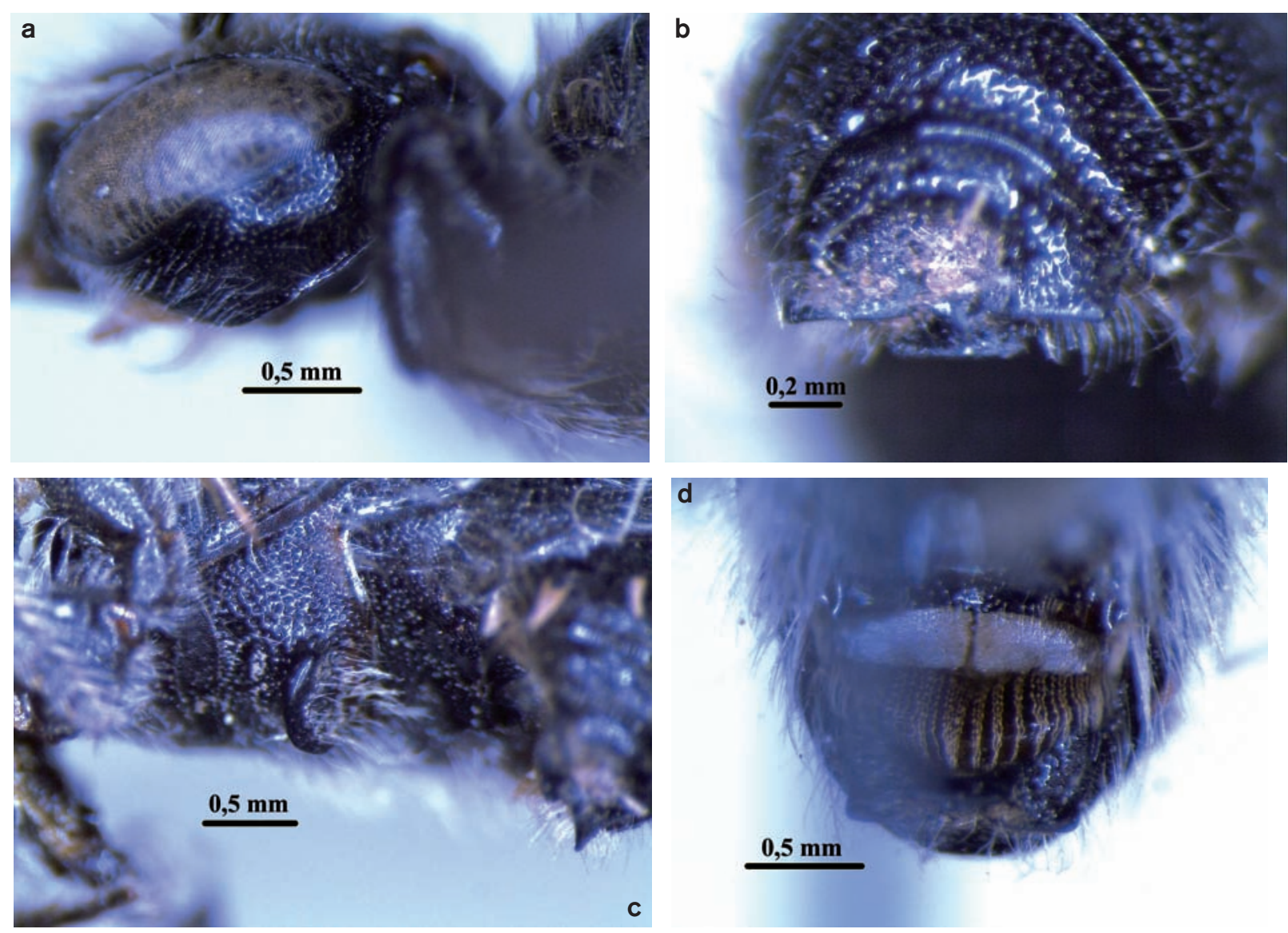

Fig. 14.- Chelostoma rapunculi $\sigma^{7}$. a) Carena preoccipital. b) $T_{7}$. c) $E_{2}$. d) $E_{5}$.

Fig. 14.- Chelostoma rapunculi $\sigma^{7}$. a) Preoccipital carina. b) $T_{7}$. c) $E_{2}$. d) $E_{5}$.

Calatrava, 1902, 1 ㅇ , $10^{\pi}$, La Fuente leg., MNCN. Granada: Torviscón, Sierra Nevada, 30SVF7381, 24-V-1987, $10^{7}$, F.J. Ortiz-Sánchez leg., FJOS. Huesca: Biescas, 9-VII-2009, $30^{7} \sigma^{7}$, C. Ornosa leg., UCM; V. de Ordesa, 1 ㅇ, $10^{7}$, Dusmet leg., MNCN. La Rioja: Montenegro, Rodezno, 2007, 1 우, L. Baños leg.; Ventosa, 2007, 2 우 오 L. Baños leg., UCM. Madrid: El Pardo, El Goloso, 1-8-VI-1991, 1 ㅇ , Nieves y Rey leg., USAL; El Ventorrillo, $1480 \mathrm{~m}, 7-14-\mathrm{VII}-1989,10^{7}$, Nieves y Rey leg., USAL. Salamanca: Poblado Saucelle, 23V-1998, $30^{x} \sigma^{x}$; 1-15-VI-1998, 3 우 우, $20^{x} \sigma^{x}$; 6-VI-1998, 1 우,

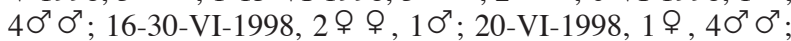
1-15-VII-1998, 1 우, , 5-VII-1998, 2 우 우, $10 \sigma^{7} \sigma^{7} ; 18$-VII-1998, 2 우 우, $10^{7}$; Salto Saucelle, 26-IV-1997, $10^{7}$; Saucelle, arriba, 16-31-V-2001, 1 우 ; 25-V-1997, 1 우, $10^{7} ; 12-\mathrm{VI}-1997,10^{\text {" }}$; 22-VI-1997, 1 ㅇ ; 20-VII-1997, 1 ㅇ ; Gayubo et al. leg., USAL; Salto Aldeadávila, 20-VI-1998, $20^{7} \sigma^{7}$; 5-VII-1998, 4 ㅇ 우 ; 18VII-1998, 2 우 우; Gayubo et al. leg., USAL; San Martín del Castañar, 30-VI-1999, 1 ㅇ ; 15-VI-1999, 1 ㅇ ; Gayubo et al. leg., USAL. Toledo: Paredes de Escalona, 15-VI-1999, 2 우 우; 30-VI-1999, 1 오, Gayubo et al. leg., USAL.

Graellsia, 68(2), Diciembre 2012, pp. 263-280 - ISSN: 0367-5041 doi:10.3989/graellsia.2012.v68.058

\section{Conclusiones}

Se incluyen en este trabajo las claves ibéricas de hembras y machos del género Chelostoma, acompañadas de ilustraciones originales. Tanto las claves como las imágenes incluidas, dibujos y fotografías, son inéditas.

Se aportan nuevas citas y actualización o modificación de registros antiguos, que amplían la distribución ibérica conocida de Chelostoma campanularum, Chelostoma distinctum, Chelostoma edentulum, Chelostoma emarginatum, Chelostoma florisomne, Chelostoma foveolatum y Chelostoma rapunculi. Algunas de estas son además de mayor relevancia al conocerse previamente en el territorio ibérico solo por medio de un ejemplar o cita, como en el caso de Chelostoma foveolatum y Chelostoma rapunculi, cuyas citas actuales amplían notablemente su distribución conocida en nuestro territorio. 

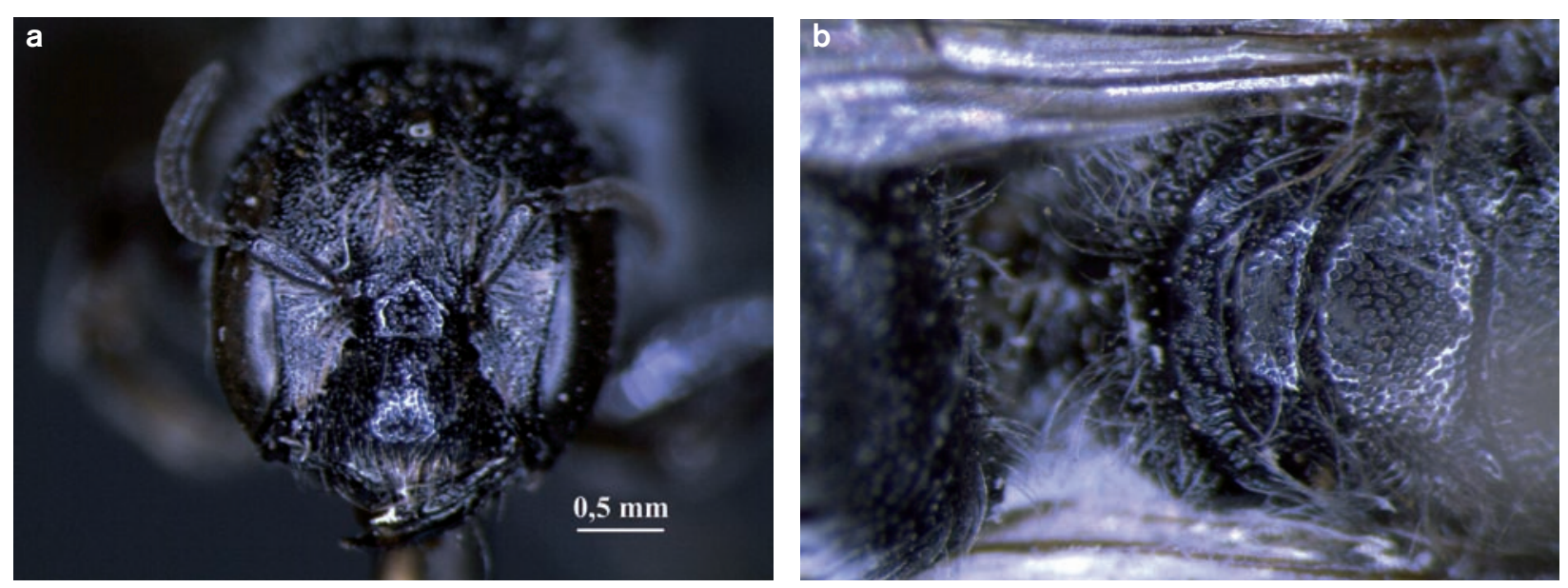

Fig. 15.- Chelostoma nasutum 오 a) Clípeo. b) Propodeo (área horizontal).

Fig. 15.- Chelostoma nasutum 우 . a) Clypeus. b) Propodeum (horizontal area).

\section{Agradecimientos}

A los Doctores Isabel Izquierdo, Amparo Blay, Mercedes París y Miguel Ángel Alonso Zarazaga, por las facilidades para el acceso a las colecciones del Museo Nacional de Ciencias Naturales de Madrid y de otras instituciones; a los museos de París (Muséum national d'Histoire naturelle, Dr. L. Albenga) y Berlín (Museum für Naturkunde, Dr. F. Koch) por el préstamo desinteresado de los tipos de algunas de las especies estudiadas. Los dibujos han sido realizados por Iñaki Díez Cortaberría y Alexandre Anichtchenko, en el Proyecto Fauna Ibérica, al que pertenece el copyright de los mismos.

\section{Referencias}

Amiet, F., Herrmann, M., Müller, A. \& Neumeyer, R., 2004. Apidae 4: Anthidium, Chelostoma, Coelioxys, Dioxys, Heriades, Lithurgus, Megachile, Osmia, Stelis. Fauna Helvetica. Vol. 9. Centre Suisse de Cartographie de la Faune (CSCF)/Schweizerische Entomologische Gesellschaft (SEG). Neuchâtel. 274 pp.

Banaszak, J. \& Romasenko, L., 1998. Megachilid bees of Europe (Hymenoptera, Apoidea, Megachilidae). 2nd edition (corrected and supplemented). Bydgoszcz University. Bydgoszcz. 239 pp.

Benoist, R., 1929. Les Heriades de la faune française (Hym. Apidae). Annales de la Société Entomologique de France, 98: 131-141.

Bofill, J. M., 1905. Catàlech de Insectes de Catalunya. Hymenòpters. Butlletí de la Institució Catalana d' Historia Natural, 7: 41-47; 8: 48-53.

Ceballos, G., 1956. Catálogo de los himenópteros de España. Trabajos del Instituto Español de Entomología (C.S.I.C.). Madrid. 554 pp.
Diniz, M. A., 1989. Catálogo das abelhas portuguesas -I. Ciência Biológica: Ecología e Sistemática, 9: 33-39.

Dubitzky, A., Blank, S. M. \& Schönitzer, K., 2005. Die Hymenopterenfauna (Symphyta, Aculeata) im Norden von Dachau, Bayern. Linzer biologische Beiträge, 37(1): 235-314.

Griswold, T. L. \& Michener, C. D., 1998. The classification of the Osmiini of the Eastern Hemisphere (Hymenoptera, Megachilidae). Journal of the Kansas Entomological Society, [1997], 70(3): 207-253.

Maidl, F., 1922. Beiträge zur Hymenopterenfauna Dalmatiens, Montenegros und Albaniens. Annalen des Naturhistorischen Museums in Wien, 35: 36-106.

Michener, C. D., 1997. Genus-group names of bees and supplemental family-group names. Scientific Papers, Natural History Museum. The University of Kansas, 1: $1-81$.

Michener, C. D., 2007. The bees of the World. Second edition. The Johns Hopkins University Press. Baltimore. xvi +953 pp.

Müller, A., 2012. Palaearctic Osmiine Bees. ETH Zürich. http://blogs.ethz.ch/osmiini

Ornosa, C., Torres, F. \& Ortiz-Sánchez, F. J., 2006. Catálogo de los Megachilidae del Mediterráneo occidental (Hymenoptera, Apoidea). I. Osmiini. Graellsia, 62(2): 223-260.

Ortiz-Sánchez, F. J., 1992. Los “ápidos” de la provincia de Almería, nuevas aportaciones (Hymenoptera. Apoidea). Boletim da Sociedade Portuguesa de Entomologia, Supl. 3: 623-632.

Ortiz-Sánchez, F. J., 2012. Lista actualizada de las especies de abejas de España (Hymenoptera: Apoidea: Apiformes). Boletín de la Sociedad Entomológica Aragonesa, 49: 265-281. 

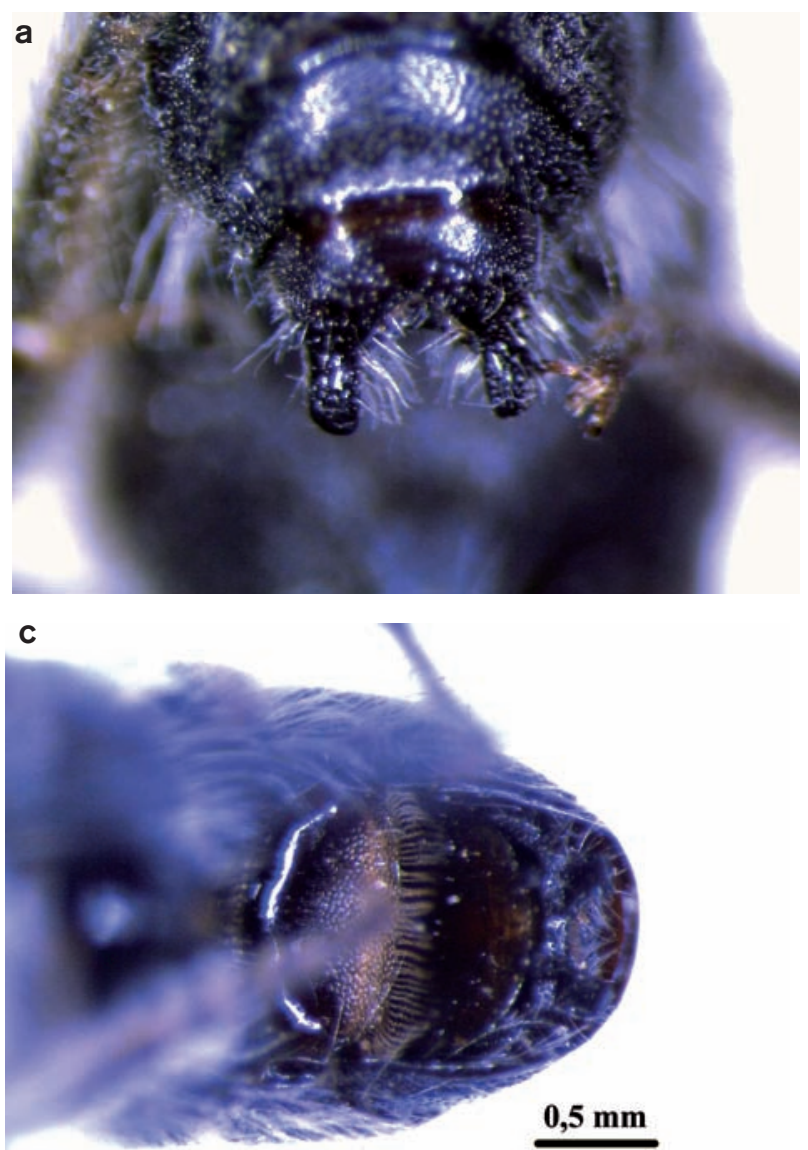

Ortiz-Sánchez, F. J., Ornosa, C. \& Torres, F., 2008. Primera cita de Chelostoma (Chelostoma) edentulum Pérez, 1895 en Europa (Hymenoptera, Megachilidae). Boletín de la Asociación española de Entomología, 32(1-2): 183-186.

Pérez-Íñigo, C., 1984. Los Ápidos de la Sierra de Guadarrama II. Fam. Andrenidae y Megachilidae (Hym., Apoidea). Graellsia, [1983], 39: 103-126.

Praz, C. J., Müller, A., Danforth, B. N., Griswold, T. L., Widmer, A. \& Dorn, S., 2008. Phylogeny and biogeography of bees of the tribe Osmiini (Hymenoptera: Megachilidae). Molecular Phylogenetics and Evolution, 49: 185-197.

Scheuchl, E., 1996. Illustrierte Bestimmungstabellen der Wildbienen Deutschlands und Österreichs. Vol. 2, Megachilidae-Melittidae. Published by the author. Velden. 116 pp.

Ungricht, S., Müller, A. \& Dorn, S., 2008. A taxonomic catalogue of the Palaearctic bees of the tribe Osmiini (Hymenoptera: Apoidea: Megachilidae). Zootaxa, 1865: 1-253.

Warncke, K., 1986. Die Wildbienen Mitteleuropas, ihre gültigen Namen und ihre Verbreitung. Entomofauna (Ansfelden), Supplement 3: 1-128. b

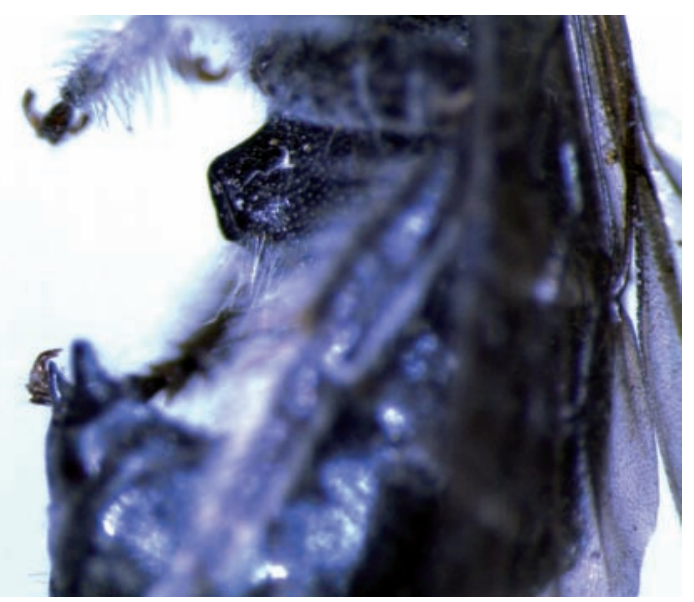

Fig. 16.- Chelostoma nasutum $\sigma^{7}$. a) $T_{7}$. b) $E_{2}$. c) $E_{4}-E_{5}$.

Fig. 16.- Chelostoma nasutum $\sigma^{7}$. a) $T_{7}$. b) $E_{2}$. c) $E_{4}-E_{5}$.

Warncke, K., 1991. Die Bienengattung Osmia Panzer, 1806, ihre Systematik in der Westpaläarktis und ihre Verbreitung in der Türkei. 7. Die Untergattung Foveosmia subg. nov. Linzer biologische Beiträge, 23(1): 267-281.

Westrich, P. \& Dathe, H. H., 1997. Die Bienenarten Deutschlands (Hymenoptera, Apidae): Ein aktualisiertes Verzeichnis mit kritischen Anmerkungen. Mitteilungen - Entomologischer Verein Stuttgart, 32: 1-34. 